\title{
Effects of different gas flow rates and non-perpendicular incidence angles of argon cold atmospheric-pressure plasma jet on silver thin film treatment
}

\author{
Maryam Hosseinpour $^{1} \cdot$ Akbar Zendehnam $^{1} \cdot$ Seyedeh Mehri Hamidi Sangdehi ${ }^{2} \cdot$ Hamidreza Ghomi Marzdashti $^{2}$
}

Received: 12 April 2019 / Accepted: 21 September 2019/ Published online: 30 September 2019

(c) The Author(s) 2019

\begin{abstract}
In this study, the influences of variations in the gas flow rate and incidence angles of argon cold atmospheric-pressure plasma jet on the morphology and absorption spectra of silver thin films $(60 \mathrm{~nm}, 80 \mathrm{~nm}$, and $100 \mathrm{~nm}$ film thickness) are investigated. To evaluate the surface morphology, atomic force microscopy (AFM) was employed on the silver thin film surface before and after plasma processing. To analyze the effect of plasma treatment on the grain size, the one-dimensional AFM surface profiles of Ag thin films are approximated using a Gaussian function. The absorbance of Ag thin films is measured in wavelength range of 190-1100 nm utilizing UV-Vis absorption spectrometer. Compared to the gas flow rates 0.5 standard litter per minute (SLM) and 2 SLM, surface treatment of Ag thin film with gas flow rate of 1 SLM increased the valley depth, the peak valley height, and the distance between two deepest valleys remarkably. A sequential argon plasma treatment (2-min plasma treatment perpendicular to surface was followed by 2-min plasma processing with non-perpendicular incidence angle of $60^{\circ}$ ) offers considerable improvement in the uniformity of grains and also changes shape of grains, especially the peak height (about 44 times higher than untreated sample) and area of grains (almost 136 times greater than untreated sample) which can be applicable for optical sensing technology.
\end{abstract}

Keywords Non-perpendicular incidence angle of argon cold atmospheric-pressure plasma jet (APPJ) · Gas flow rate Absorption spectra $\cdot$ Surface morphology $\cdot$ Analysis of silver grain size $\cdot$ Gaussian function

\section{Introduction}

Nanostructured silver particles (Ag NPs) have attracted much attention in various fields of science and technology such as in catalysts, medicine, antimicrobial, and organic pollutants decomposition due to their unique and diverse properties (their non-hazardous nature and optical characteristics) [1-5]. In contrast to their corresponding bulk counterparts, metallic nanoparticles can absorb electromagnetic radiation, resulting in surface plasmon resonance (SPR) at the metal-dielectric interface [4]. It is also reported that the $\mathrm{Ag} / \mathrm{TiO}_{2}$ thin films are promising nano-materials

Maryam Hosseinpour

maryamhosseinpour35@yahoo.com

1 Department of Physics, Faculty of Science, Arak University, P.O. Box: 3848177584, Arak, Iran

2 Laser and plasma Research Institute, Shahid Beheshti University (SBU), P.O. Box: 1983969411, Evin, Iran in self-cleaning and antimicrobial technologies because of their significant antibacterial potential against such microorganisms as Gram-negative bacteria Escherichia coli ( $E$. coli) $[6,7]$.

With the increasing demand for real-time monitoring of environmental, gas, food, and health applications, silver and gold are the preferred materials for the SPR sensor devices due to the fact that they are chemically stable while providing good sensitivity to refractive index changes [8-10]. Indeed, silver nanoparticles have significant antimicrobial activity against living cells, fungi, bacteria, or other microorganisms even with low concentrations.

Two main factors, (i) physicochemical characteristics of nanoparticles and (ii) type of bacteria, play important roles in antibacterial activities of Ag NPs [11].

One of the most important parameters in nano-technology and thin films is surface and its roughness, since it is the first interface of material which may interact with other materials and with environment. As we know, in SPR sensor devices, usually the metallic sensing layer has a short life span that 
depends on the environment within which the sensor operates. In harsh environments, the performance of SPR sensor may decrease when the quality of sensing layer degrades. Moreover, it is reported that the antibacterial activity of Ag NPs is size and shape dependent $[12,13]$. Therefore, in recent years, a lot of efforts have been directed into the modification of surface roughness of thin films, resulting in the improvement in grain size [14], surface energy [15] and such properties as wettability (hydrophilic or hydrophobic) $[16,17]$, formation of highly reactive chemical species, in particular reactive oxygen (ROS) [18] and nitrogen species (RNS) [19] on the metallic thin film surfaces. As a result, to enhance the stability and durability, sensitivity, and antimicrobial activity of SPR sensors based on thin films, their surfaces should be modified by cold plasma (CP) treatment. Cold plasma treatment is one of the most versatile non-thermal techniques in surface modification [20-25]. Plasma can be classified as high pressure, atmospheric pressure and low pressure according to the pressure conditions. Cold atmospheric plasma (CAP) is known as non-thermal because it has electrons at a hotter temperature than the heavy particles that are at room temperature. Applications of CAP include: sterilization of medical equipment, packaging in the food industry, wound healing, and such dental applications as dental caries, elimination of biofilms, and bleaching [26, 27].

Two promising technologies for producing cold atmospheric plasmas (CAP), especially in food industries and medical applications, are dielectric barrier discharge (DBD) and jet plasma [20-25, 28, 29]. In our early work, an argon dielectric barrier discharge reactor with atmospheric pressure for material treatment (treatment of aluminum, glass (quartz), and silicon) was simulated and analyzed using COMSOL Multiphysics v5.0 software [30]. Plasma jet devices consist of two concentric electrodes, where the inner electrode is typically connected to a radio frequency $(\mathrm{RF})$ power at high frequency resulting in ionization of the working gas, which exits the nozzle with a jet-like configuration [31]. Broadly, the configuration and length of plasma plume can be influenced by the jet design, the electric filed geometry, as well as by the such experimental conditions as the gas flow rate, the feed gas composition (noble gases or molecular gases), the discharge excitation parameters (the applied voltage, excitation frequency, input power) [32-35]. Most of the cold atmospheric-pressure plasma jets (APPJs) are working with a noble gas (Ar, He, etc.) with a small percentage of such reactive gases as $\mathrm{O}_{2}$ or $\mathrm{N}_{2}$, which are classified into four categories: dielectric-free electrode (DFE) jets, DBD jets, DBD-like jets, and single electrode (SE) jets [36]. Since one of the major drawbacks of single APPJs is the small size of the treated areas, utilization of arrays of plasma jets has been also proposed to enlarge the treated area [37]. However, employing arrays of plasma jets still needs some considerations to improve their performances for surface treatment with large area. Indeed, the control of spatial uniformity of the plasma jet array can require more effort when dealing with plasma jets. For example, Zehang et al. [38] studied the effect of $\mathrm{O}_{2}$ additive on the improvement in spatial uniformity of one-dimensional helium plasma jet array. In addition, Wang et al. [39] optimized such experimental parameters as the ground electrode position, gas flow rate, and pulse frequency to study the uniformity of a microsecond pulse-driven argon plasma jet array. Recently, the relationship between the behaviors of different arrays of a radial plasma jet with the presence of various cylindrical targets has been investigated [40]. Many works have been focused on the enhancement of photo-catalytic and antibacterial activities of different nanostructures using atmospheric-pressure DBD systems, for example: $\mathrm{Ag} / \mathrm{TiO}_{2}$ nano-composites [41, 42], $\mathrm{Au} / \mathrm{TiO}_{2}$ catalyst [43, 44], and $\mathrm{Pt} / \mathrm{TiO}_{2}$ photo-catalyst [45].

Numerous studies have been focused on the treatment of polymeric surfaces [21-23], natural organic materials (e.g., cellulosic materials such as paper and cotton) [46, 47], and inorganic materials (e.g., metals) [26, 30, 48-50]. On the other hand, a few recent studies [51] reported the utilization of cold plasma jets for the treatment of metallic thin film surfaces to improve their SPR metal nanoparticles-based optical sensing properties which is effective for detection of chemical and biological targets. Furthermore, Talukder et al. [52] used oxygen, hydrogen, and nitrogen jet plasmas (molecular feed gases) to improve electrical and optical property of the zinc oxide thin films using different types of working gas (employing both separated and sequential oxygen, hydrogen, and nitrogen plasma treatment). In addition, in our early work, the influence of non-thermal plasma jet ( $\mathrm{He}$ and $\mathrm{Ar}$ ) was studied to improve the antibacterial activity, surface roughness, and hydrophilic property of Ag thin films [53].

Among the various operational parameters of an APPJ, the gas flow rate has undoubtedly a key role in the propagation of the plasma outside the source on the substrate and affects significantly the shape and length of plasma plume for surface processing. However, as we know, the other parameters such as duration of exposure time, type of working gas as well as nozzle distance to treated sample are the most factors which have been investigated [21, 23, 52-54]. For instance, R. Zhou studied the effects of different working gases $\left(\mathrm{N}_{2}, \mathrm{He}, \mathrm{O}_{2}\right.$ as well as air) and applied voltage on the photo-catalytic property of $\mathrm{TiO}_{2}$ for inactivation of $E$. coli cells in aqueous media under various exposure times (0-5 min) using atmospheric-pressure microplasma array (29 microplasma jet units) [55]. Furthermore, the studies on the subject of SPR metal nanoparticles-based optical sensing focused only for plasma treatment at the low pressure $[54,56]$. Indeed, as far as we know, the effects of jet plasma with different gas flow rates and non-perpendicular 
incidence angles $\left(30^{\circ}\right.$ and $\left.60^{\circ}\right)$ for surface modification of such metallic thin films as silver to enhance its optical sensing activity have not yet been reported.

Therefore, employing cold Ar APPJ with different gas flow rates (0.5 SLM, 1 SLM, and 2 SLM) and two nonperpendicular incidence angles $\left(30^{\circ}\right.$ and $\left.60^{\circ}\right)$, the main aim of the present work is to investigate the surface morphology and absorbance spectrum of Ag thin films. Thus, the work is organized as follows: A detailed description of the experimental tools and analytical software employed in this research is presented in "Experimental and analytical details" section. Using atomic force microscopy (AFM), the influence of different gas flow rates of argon APPJ (0.5 SLM, 1 SLM, and 2 SLM) on the surface morphology of Ag thin films $(60 \mathrm{~nm}$ and $80 \mathrm{~nm}$ ) is studied in "Effects of different gas flow rates (0.5 SLM, 1 SLM, and 2 SLM) on the surface morphology of Ag thin films" section as the other operational parameters of jet are kept constant. UV-Vis absorption spectrometer in the wavelength range of $190-1100 \mathrm{~nm}$ was employed in "Influences of different non-perpendicular jet plasma processing $\left(30^{\circ}\right.$ and $\left.60^{\circ}\right)$ on the surface morphology and optical property of Ag thin films" section to investigate the effect of a sequential plasma treatment [2-min plasma treatment perpendicular to surface (in "Effects of different gas flow rates (0.5 SLM, 1 SLM, and 2 SLM) on the surface morphology of Ag thin films" section) was followed by 2-min plasma treatment with non-perpendicular incidence angle $\left(60^{\circ}\right)$ in this section] and a treatment with incidence angle of $30^{\circ}$ on the absorbance spectrum of $\mathrm{Ag}$ thin films with thicknesses $80 \mathrm{~nm}$ and $100 \mathrm{~nm}$, respectively. Please note that in "Effects of different gas flow rates $(0.5$ SLM, 1 SLM, and 2 SLM) on the surface morphology of Ag thin films" and "Influences of different non-perpendicular jet plasma processing $\left(30^{\circ}\right.$ and $\left.60^{\circ}\right)$ on the surface morphology and optical property of Ag thin films" sections, a Gaussian function is used to approximate the grain size (full width at half maximum (FWHM), peak height as well as area of grains) in the one-dimensional (1D) AFM profiles by XY Extract Graph Digitizer v5.1 and Origin Pro v8.6 software. Finally, conclusion is explained in "Conclusion" section. Experimental results show that surface treatment of $\mathrm{Ag}$ thin film with gas flow rate 1 SLM increased the valley depth, the peak valley height, and the distance between two deepest valleys remarkably compared to the gas flow rates 0.5 SLM and 2 SLM. The results of UV-Vis absorption spectrometer illustrated that peak of the maximum absorbance of Ag thin film with thickness $80 \mathrm{~nm}$ was found to be red-shifted by $12 \mathrm{~nm}$ after sequential Ar plasma treatments (2-min plasma processing perpendicular to surface was followed by 2-min plasma treatment with non-perpendicular incidence angle of $60^{\circ}$ ). The achievements also demonstrate that maximum absorbance peak of $\mathrm{Ag}$ thin film with thickness $80 \mathrm{~nm}$ increased from 42 to $55 \%$ after sequential $\mathrm{Ar}$ plasma treatments, which is in good agreement with the results obtained from the presented analytical method for evaluation of grain sizes. The Ar jet plasma treatment with angle of $60^{\circ}$ seems to be more effective in not only improvement in surface morphology but also enhancement of the absorbance maximum peak.

\section{Experimental and analytical details}

\section{Deposition details}

Thin films were deposited by magnetron sputtering method (Hind High Vacuum, H.H.V, 12'MSPT) on glass substrate. This deposition technique offers such acceptable advantages as high deposition rates, low substrate temperature, good adhesion of thin film to glass substrate, and finally, films with good packing density [57]. The base pressure of vacuum system was around $10^{-6} \mathrm{~m}$ bar. Circular glass disks with diameters of $2 \mathrm{~cm}$ and $3 \mathrm{~cm}$ as well as thickness of $1 \mathrm{~mm}$ were used as substrates. A circular flat disk of silver ( $\mathrm{Ag}$ ) (99.9\% purity) with thickness of $3 \mathrm{~mm}$ and diameter of $125 \mathrm{~mm}$ was employed as target (cathode). Before deposition, the substrates were carefully cleaned in heated acetone ultrasonic bath for $2 \mathrm{~min}$. Substrate temperature was monitored during deposition by a digital thermocouple which was placed on substrate holder (namely $300 \mathrm{~K}$ ). The distance between target and substrate was maintained at $12 \mathrm{~cm}$ (optimum distance). The coating rate of $1 \AA / \mathrm{S}$ and $\mathrm{Ag}$ thin film thickness was measured by a vibrating quartz crystal thickness monitor. The Ag thin films with thicknesses of $60 \mathrm{~nm}$, $80 \mathrm{~nm}$, and $100 \mathrm{~nm}$ were obtained.

\section{Details of plasma processing for perpendicular APPJ}

The applied jet plasma in this work, as shown in Fig. 1a, $\mathrm{b}$, is based on a DBD-like jet which consists of a dielectric tube with one metal ring ground electrode on the outer side of the tube and with a centered pin electrode as the highvoltage (HV) electrode. One of the most important advantages of this jet plasma device with such configuration is that the electric field along the plasma plume is enhanced and favorable for generating long plasma plumes and more active plasma chemistry [58]. Moreover, the ground ring electrode on the outer side of the tube causes the discharge inside the tube to be enhanced. Indeed, this jet plasma has such advantages as the gas temperature of the plasma remains close to the room temperature due to the low power density delivered to the plasma [36]. To avoid oxidation, carbonation or nitration of the Ag thin film surface with such molecular gases as $\mathrm{O}_{2}$, air and $\mathrm{N}_{2}$, in this work, argon (Ar) is used as the working gas. In addition, in our early work [53], Ar plasma offered an acceptable antibacterial activity for removal of $E$. 

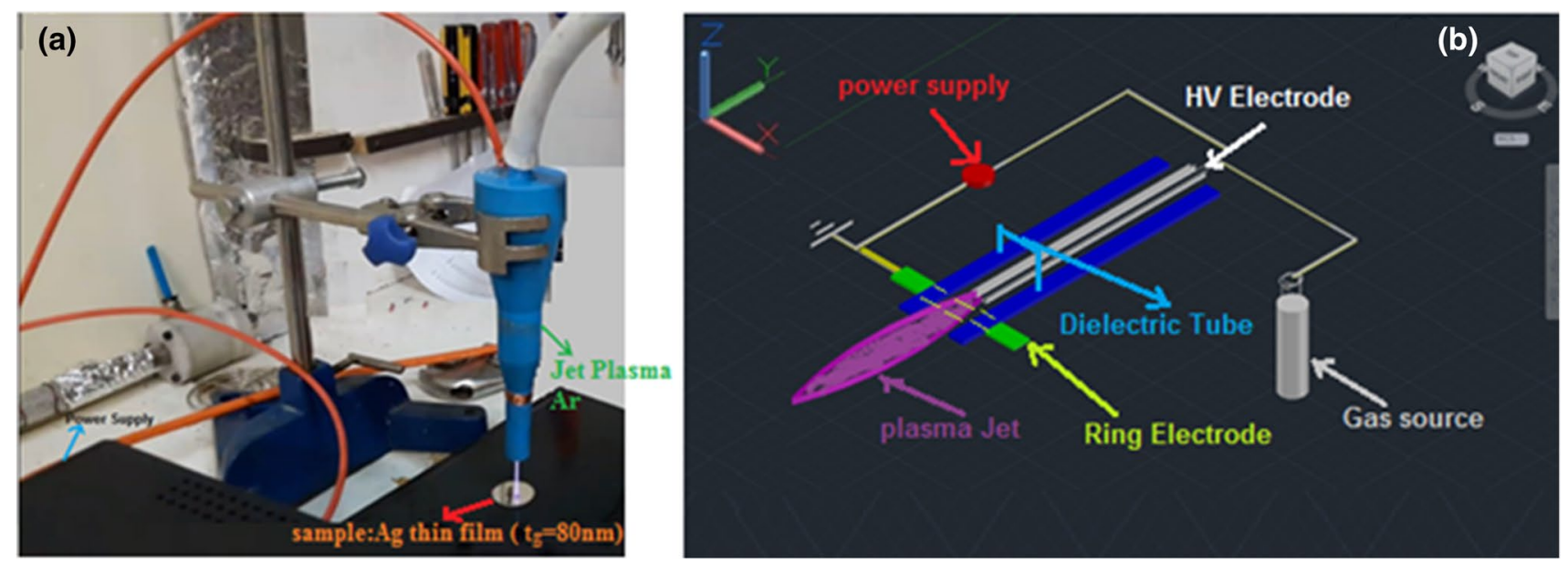

Fig. 1 a Experimental setup for perpendicular jet plasma treatment and b 3D schematic setup of cold APPJ in Auto CAD v2014

Table 1 Values of operational parameters for the perpendicular jet plasma treatment with variable gas flow rate 0.5 SLM, 1 SLM and 2 SLM

\begin{tabular}{llllll}
\hline $\begin{array}{l}\text { Applied voltage } \\
(\mathrm{KV})\end{array}$ & $\begin{array}{l}\text { Treatment time } \\
(\mathrm{min})\end{array}$ & $\begin{array}{l}\text { Nozzle-to-sample } \\
\text { distance }(\mathrm{cm})\end{array}$ & $\begin{array}{l}\text { Plasma temperature } \\
\left({ }^{\circ} \mathrm{C}\right)\end{array}$ & $\begin{array}{l}\text { D. Cycle }(\%) \\
(\mathrm{KHz})\end{array}$ & $\begin{array}{l}\text { Applied frequency } \\
\text { Input power }(\mathrm{W})\end{array}$ \\
\hline 10 & 2 & 3 & $25-30$ & 10 & 6 \\
\hline
\end{tabular}

Table 2 Values of operational parameters for the non-perpendicular jet plasma treatment with angles of $30^{\circ}$ and $60^{\circ}$

\begin{tabular}{llllll}
\hline Gas flow rate (SLM) & $\begin{array}{l}\text { Nozzle-to-sample } \\
\text { distance }(\mathrm{cm})\end{array}$ & $\begin{array}{l}\text { Plasma temperature } \\
\left({ }^{\circ} \mathrm{C}\right)\end{array}$ & D. Cycle (\%) & $\begin{array}{l}\text { Applied voltage } \\
(\mathrm{KV})\end{array}$ & $\begin{array}{l}\text { Applied frequency } \\
(\mathrm{KHz})\end{array}$ \\
\hline 1 & $25-30$ & 10 & 10 & 6 & 30 \\
\hline
\end{tabular}

coli due to remarkable increment in the surface roughness (RMS) of Ag thin film with thickness of $120 \mathrm{~nm}$ (about $9 \mathrm{~nm}$ ) compared to He plasma. Surface modification by nonequilibrium plasmas at atmospheric pressure can be accomplished by using two different approaches, i.e., the "direct (touch mode)" and the "remote (non-touch mode)" approach $[29,59]$. The plasma treatment employed in this research is based on the direct mode, where the substrate is located in the plasma generation region and is directly exposed to the plasma plume. In this step, gas flow rate is variable parameter of jet plasma device with values of 0.5 SLM, 1 SLM and 2 SLM. However, the other operational parameters are kept constant and depicted in Table 1.

The plasma temperature in Tables 1 and 2 is measured by a digital thermocouple with accuracy of 0.1 .

To investigate the effects of Ar cold plasma perpendicular jet with various gas flow rates (0.5 SLM, 1 SLM, 2 SLM) on the surface morphology of Ag thin films, atomic force microscopy with scanning area $5 \mu \mathrm{m} \times 5 \mu \mathrm{m}$ (AFM, Nanosurf Mobile $\mathrm{S}$ ) was carried out before and after plasma processing.

\section{Details of plasma processing for non-perpendicular APPJ}

In this section, two oblique incidence angles, $30^{\circ}$ and $60^{\circ}$, are assumed for jet plasma to examine the influences of non-perpendicular plasma radiation on the surface morphology and optical property of samples. To adjust the jet plasma with angles of $30^{\circ}$ and $60^{\circ}$, simple schematics are proposed and depicted in Figs. $2 \mathrm{a}$, b and $3 \mathrm{a}, \mathrm{b}$, respectively. The experimental setups are also shown in Figs. 2c and $3 \mathrm{c}$. Here, the only variable parameter of jet plasma device is incidence angle of plasma radiation. All of the operational parameters are assumed to be constant and are given in Table 2.

The absorbance of samples were measured in wavelength range of 190-1100 nm using a UV-Vis spectrometer (Model PerkinElmer Lambda 25) before and after non-perpendicular plasma jet treatment with gas flow rate of 1 SLM.

To show the strategies employed for surface processing of Ag samples (applied approach for the $x y$-displacement 
Fig. 2 Schematic diagram of $\mathbf{a}$, $\mathbf{b}$ adjusting procedure of the jet plasma for oblique angle of $30^{\circ}$, c experimental setup
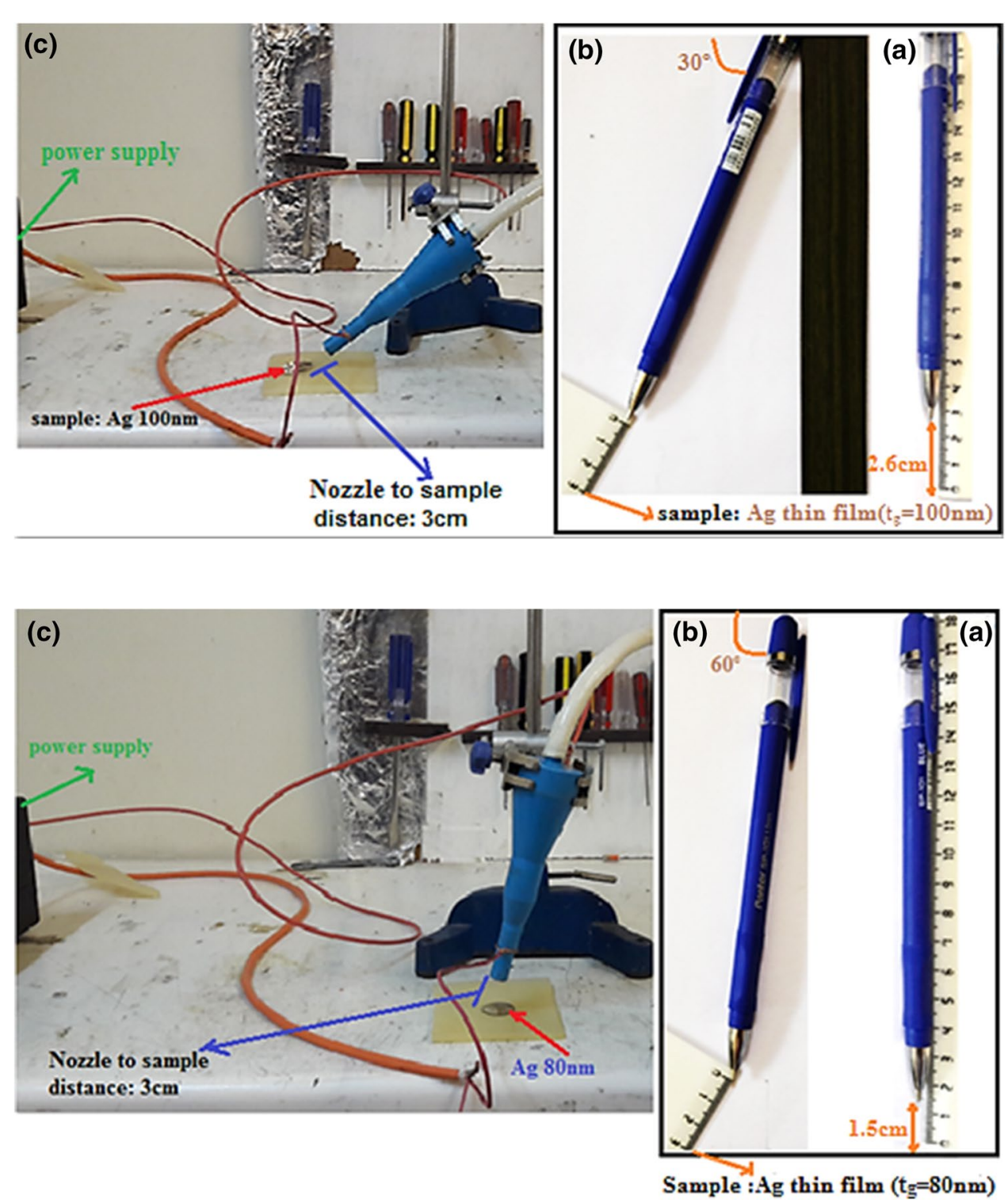

Fig. 3 Schematic diagram of $\mathbf{a}$, $\mathbf{b}$ adjusting procedure of the jet plasma for oblique angle of $60^{\circ}$, c experimental setup

of the sample holder as the plasma jet is keeping fixed), four images of surface processing of two samples are presented in Figs. 4 and 5, respectively, for total treatment time of 2 min.

\section{Details of analytical method for study of surface morphology (grain size)}

To find the main reason for the appearance of fluctuations (noise-like) on the maximum absorbance peak of Ag thin film with thickness $80 \mathrm{~nm}$ after non-perpendicular $\left(60^{\circ}\right)$ plasma jet treatment, an analytical method is employed in this section. Since it is reported that the size and shape of nano-particles can affect such optical characteristics of metallic thin film as absorption spectra [60-62], the grain size (peak height, area, and FWHM of gains) is measured and analyzed using XY Extract Graph Digitizer v5.1 and
Origin Pro v8.6 software. Here, firstly, the 1D AFM profiles are digitized using the XY Extract Graph Digitizer v5.1 software to find the coordinates of the corresponding grains with great accuracy. These obtained dots are considered as digitized data. In the following step, the digitized data of assumed grains are then approximated using the analytical software, Origin Pro v8.6, with Gaussian amp function which is defined by Eq. (1) [63]:

$h(x)=h_{0} \exp \left[\frac{-x^{2}}{2 w^{2}}\right]$

where $h(x)$ signifies the peak height of grain, the parameter $w$ is standard deviation and $x$ is a position of each point in which peak height is calculated for that point (in $\mu \mathrm{m}$ ). Please note that the measured grains are indicated by arrows in 1D AFM profiles in the corresponding figures in "Analytical 
Fig. 4 Images of the treated areas through $x y$-displacement of the Ag thin film (with thickness $80 \mathrm{~nm}$ ) sample holder using fixed Ar cold plasma jet with incidence angle of $60^{\circ}$ for total treatment time of 2 min. This Ag sample was firstly treated with perpendicular incidence angle of Ar cold plasma jet, and the corresponding results are given in "Effects of different gas flow rates $(0.5$ SLM, 1 SLM and 2 SLM) on the surface morphology of Ag thin films" section)
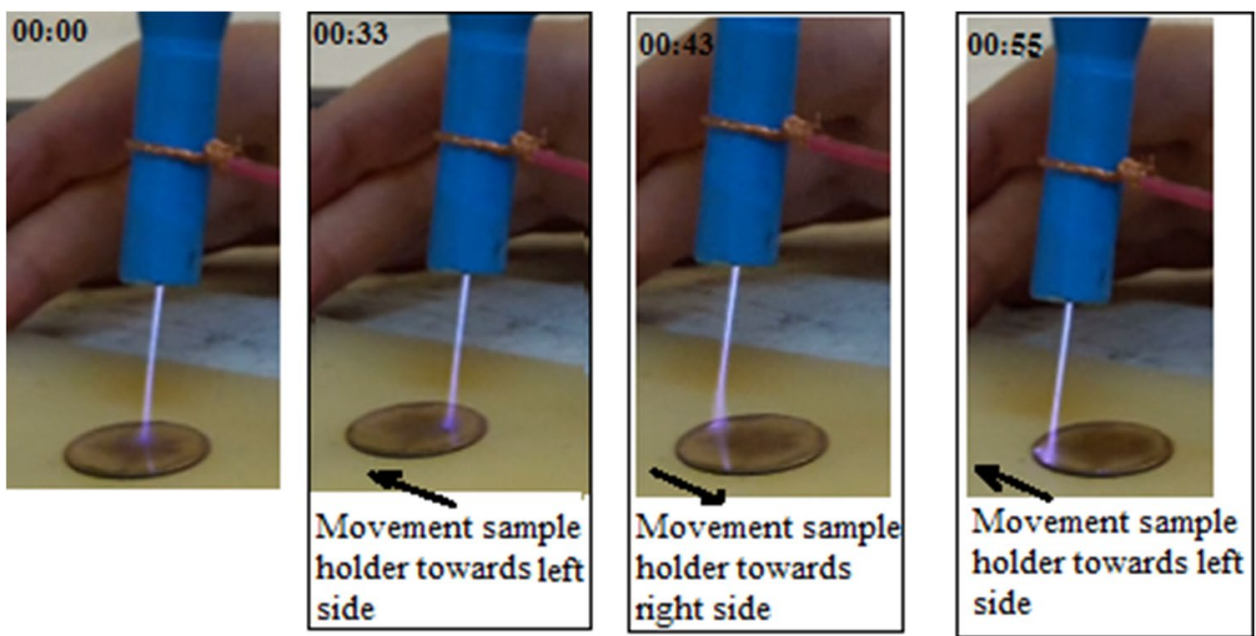

Fig. 5 Images of the treated areas through $x y$-displacement of the $\mathrm{Ag}$ thin film (with thickness $80 \mathrm{~nm}$ ) sample holder using fixed Ar cold plasma jet with incidence angle of $30^{\circ}$ for total treatment time of 2 min
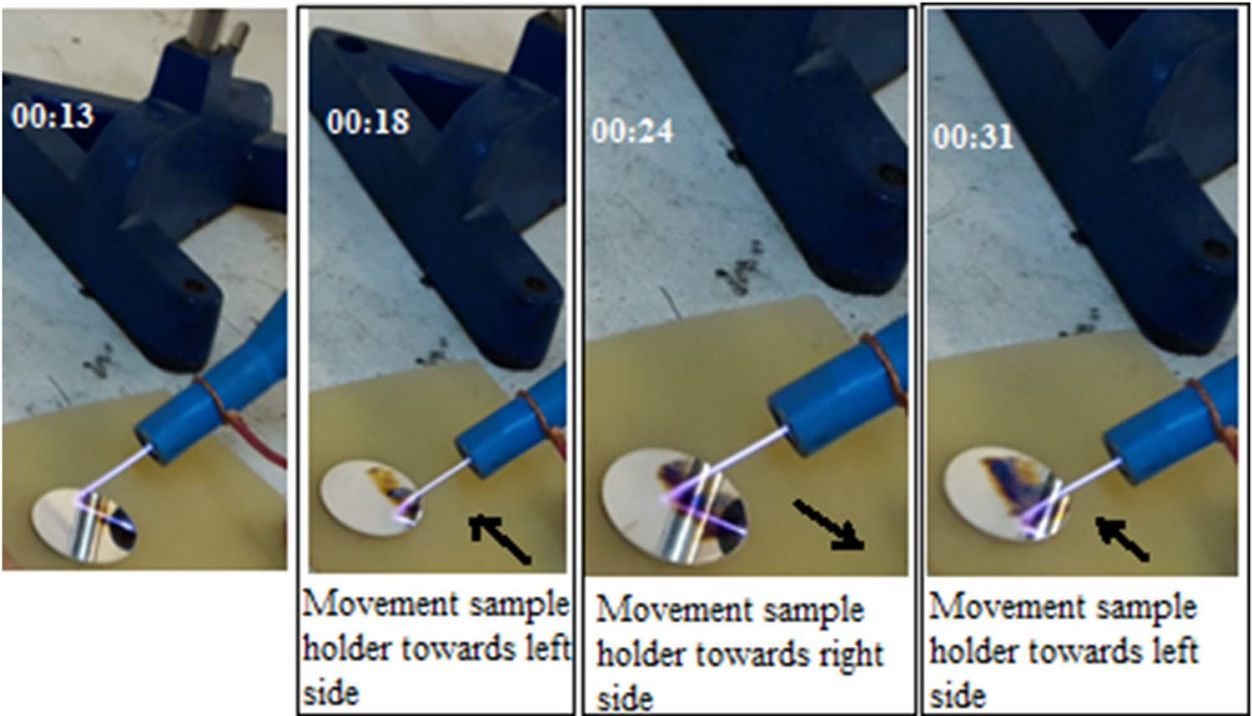

study of Ag grains before and after perpendicular plasma jet processing under different gas flow rates" and "Analytical study of Ag grains before and after non-perpendicular $\left(60^{\circ}\right)$ plasma jet processing" sections. In our previous works [64-66], this analytical method was used and the outcomes were very successful.

\section{Results and discussion}

\section{Effects of different gas flow rates (0.5 SLM, 1 SLM, and 2 SLM) on the surface morphology of $\mathrm{Ag}$ thin films}

In this section, surfaces of two Ag thin films with thicknesses of $60 \mathrm{~nm}$ and $80 \mathrm{~nm}$ are treated under conditions described in "Details of plasma processing for perpendicular
APPJ" section using Ar jet plasma shown in Fig. 1. To investigate the influence of various gas flow rates of plasma processing (0.5 SLM, 1 SLM, and 2 SLM) on the surface roughness, the roughness values for each sample were calculated from 2-dimensional and 3-dimensional (2D and 3D) AFM images of each sample $(60 \mathrm{~nm}$ and $80 \mathrm{~nm})$ and are illustrated in Figs. 6 and 7, respectively. The surface roughness of the samples was found by calculating the root mean square (RMS) of AFM data and can be evaluated by the following formula [53]:

$R(l, t)=\sqrt{\left((h(\vec{r}, t)-h)^{2}\right)_{s}}$

where $R(l, t)$ is root mean square, $h$ is average surface height and $h(\overrightarrow{\boldsymbol{r}}, t)$ is height of a point respect to a reference surface 
Fig. 6 2D and 3D AFM images of $\mathrm{Ag}$ thin film $(80 \mathrm{~nm}) \mathbf{a}$ untreated, and after Ar plasma with gas flow rate b 0.5 SLM, c 1 SLM with treatment time of $2 \mathrm{~min}$
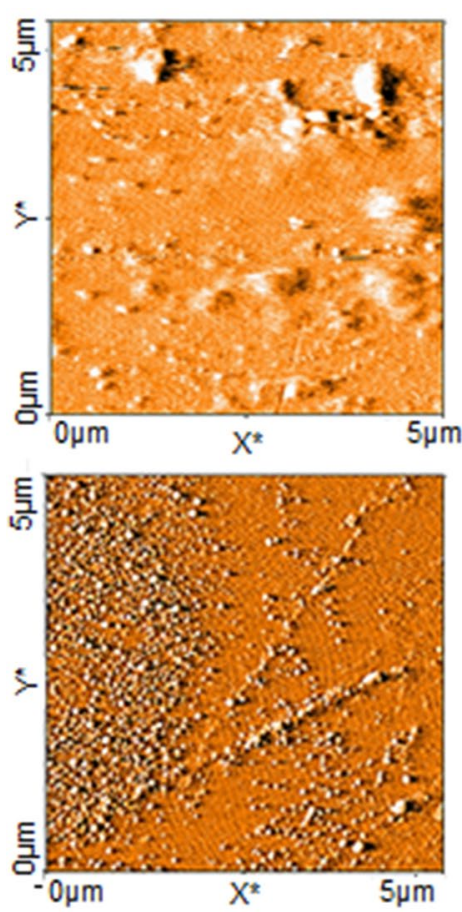

(b)
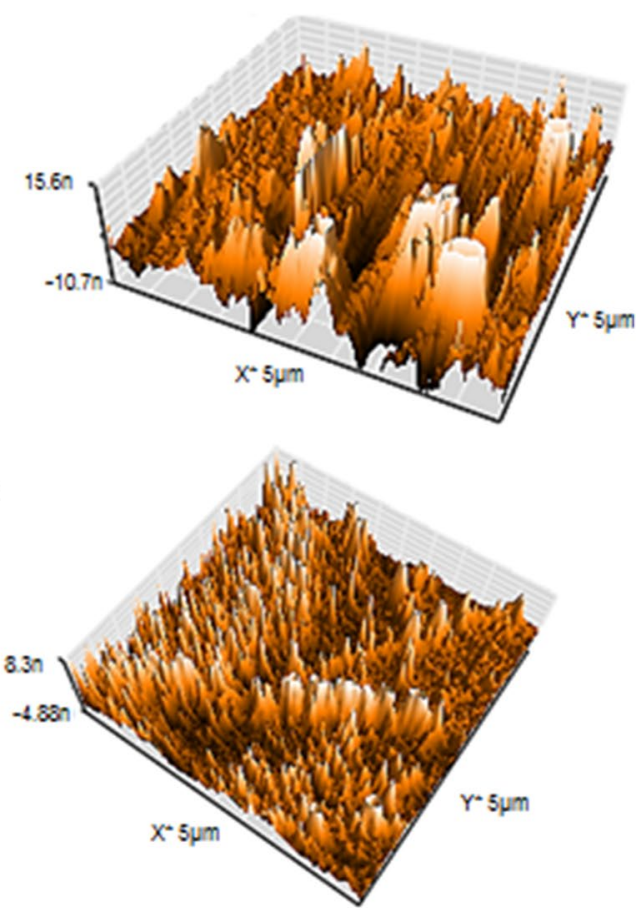

(c)

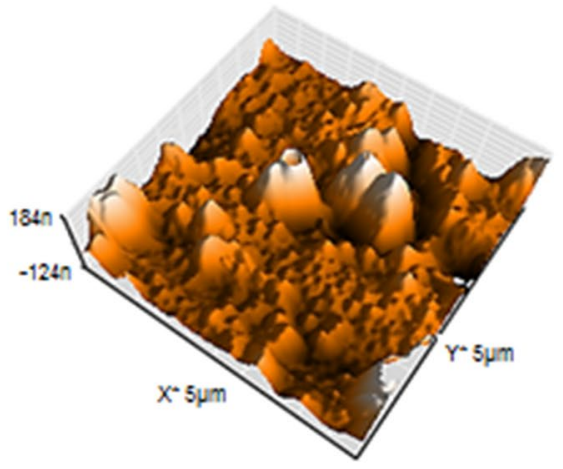

at time $t$ while $\vec{r}$ is the vector of point place. The average height $h$ for a digitized surface is shown as Eq. (3) [53]:

$h=\left((h(\vec{r}, t))_{s}\right.$

The peak valley height is the height difference between the highest and the lowest pixel in the AFM image and defined as:

$S_{y}=S_{p}-S_{v}$

where $S_{p}$ is the peak height (the highest pixel in the AFM image) and $S_{v}$ is the valley depth (the lowest pixel in the AFM image).

In addition, the distance difference between the two highest peaks $\left(S_{m 1}, S_{m 2}\right)$ and the distance difference between the two lowest valleys $\left(S_{v 1}, S_{v 2}\right)$ in the AFM image are measured and defined as:

$S_{m m}=S_{m 1}-S_{m 2}$
$S_{v v}=S_{v 1}-S_{v 2}$

Figure 6 shows that the grain sizes were decreased after plasma treatment with gas flow rate of 0.5 SLM; however, with increasing the gas flow rate to 1 SLM, the grain size grows remarkably.

As shown in Fig. 7, when the gas flow rate is increased to 2 SLM, the grain size tends to rise for Ag sample with thickness of $60 \mathrm{~nm}$. Figure 8 illustrates a column plot of RMS for samples before and after plasma treatment with different gas flow rates. As can be seen, the RMS value for both thicknesses of $60 \mathrm{~nm}$ and $80 \mathrm{~nm}$ is almost the same. According to Fig. 8, after plasma processing with three examined gas flow rates, insignificant variations can be seen in the RMS plots and the values of RMS are approximately the same for two treated samples.

To compare the effects of employing these various gas flow rates on the surface morphology of samples with 
Fig. 7 2D and 3D AFM images of $\mathrm{Ag}$ thin film $(60 \mathrm{~nm}) \mathbf{a}$ untreated, and after Ar plasma with gas flow rate $\mathbf{b} 2$ SLM with treatment time of $2 \mathrm{~min}$
Fig. 8 RMS measurements for the untreated and treated $\mathrm{Ag}$ thin films with different gas flow rates (0.5 SLM, 1 SLM, 2 SLM) for treatment time of 2 min
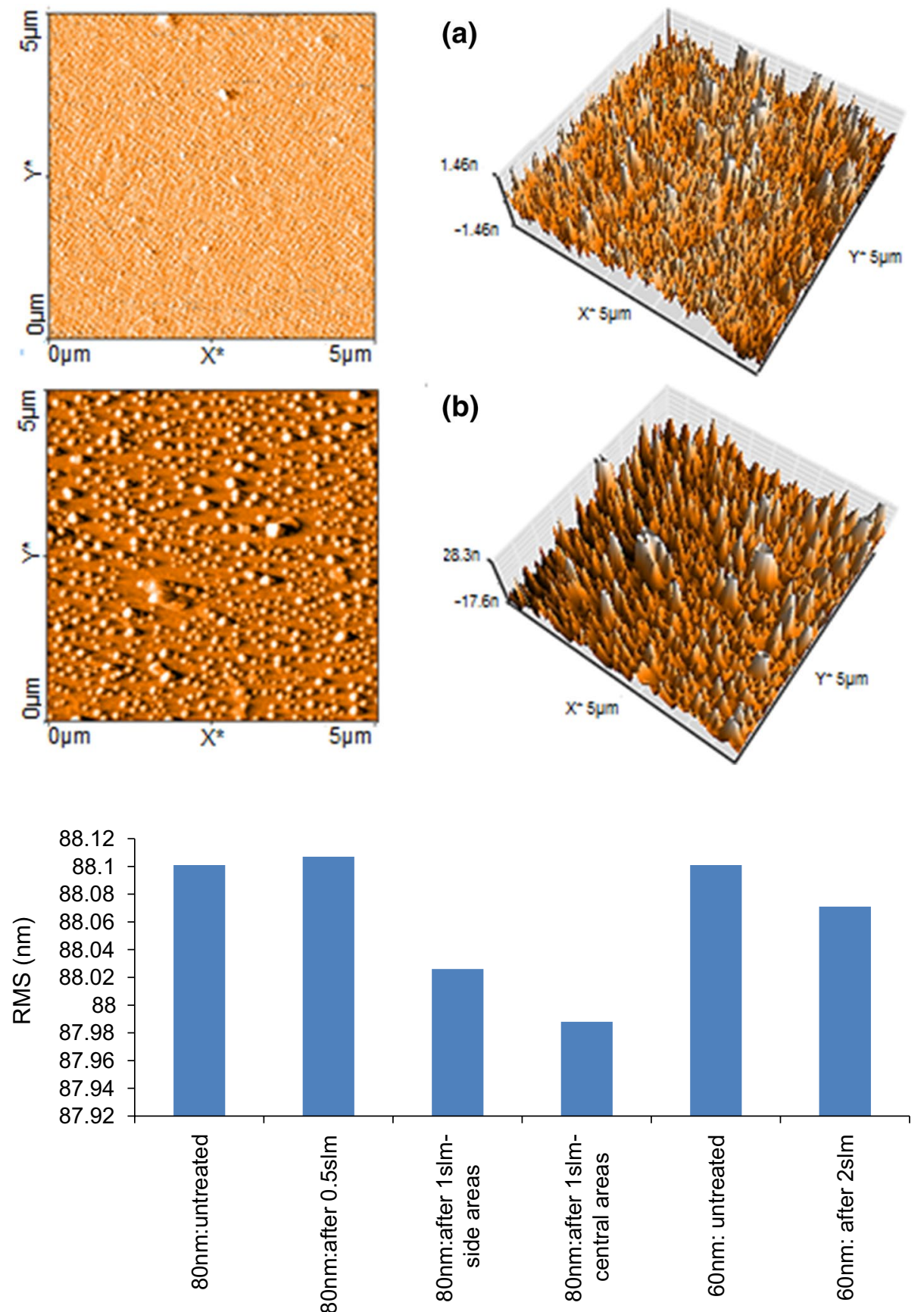

more details, the column plots for $S_{p}, S_{v}, S_{y}$, and $S_{m m}, S_{v v}$ are presented in Figs. 9 and 10, respectively.

After using gas flow rates of 0.5 SLM and 2 SLM, insignificant variations can be seen in the value of valley depths $S_{v}$, as presented in Fig. 9a. However, after plasma processing with gas flow rate 1 SLM, a different behavior can be observed for $S_{v}$ in the central and side areas of the Ag sample with thickness of $80 \mathrm{~nm}$. As shown in Fig. 9a, $S_{v}$ was increased up to $120 \mathrm{~nm}$ (about 2 times deeper than the untreated sample) in the side area of this sample; however, a noticeable decrement (almost $60 \mathrm{~nm}$ ) was obtained for $S_{v}$ in the central area. Indeed, treatment with gas flow rate of 1 SLM removes the Ag nano-particles from side area and puts these NPs into the valleys in the central area of the sample which can be seen in sputtering mechanism (see Figs. 4 and $5 \mathrm{c}$ ). For the central areas of Ag sample with thickness of $80 \mathrm{~nm}$, the amount of valley depth was so low (about $1.46 \mathrm{~nm}$ ) which in Fig. 9a cannot be seen clearly.

Figure $9 \mathrm{c}$ shows a more significant increment in the value of peak valley height $\left(S_{y}\right)$ from 40 to $140 \mathrm{~nm}$ compared to an increase in the peak height $\left(S_{p}\right)$ from $105 \mathrm{~nm}$ up to $150 \mathrm{~nm}$ in Fig. 9b. This can be due to the enhancement of valley depth 
Fig. 9 Measurements of a valley depth, b peak height and c peak valley height for the untreated and treated Ag thin films with different gas flow rates (0.5 SLM, 1 SLM, 2 SLM) for treatment time of $2 \mathrm{~min}$

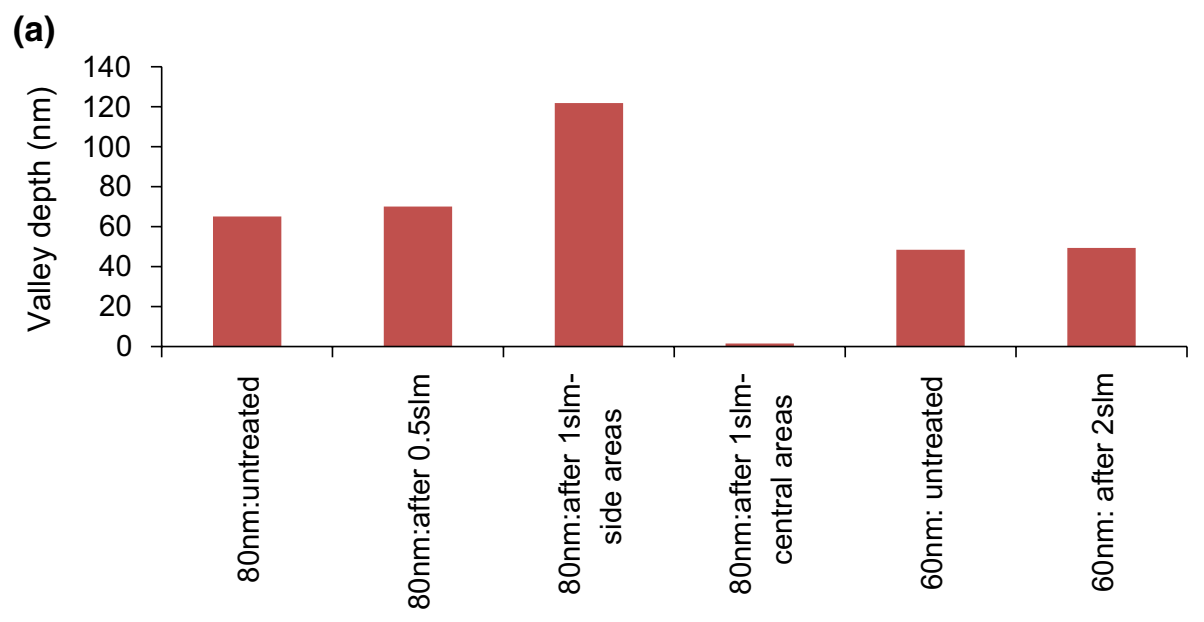

(b)

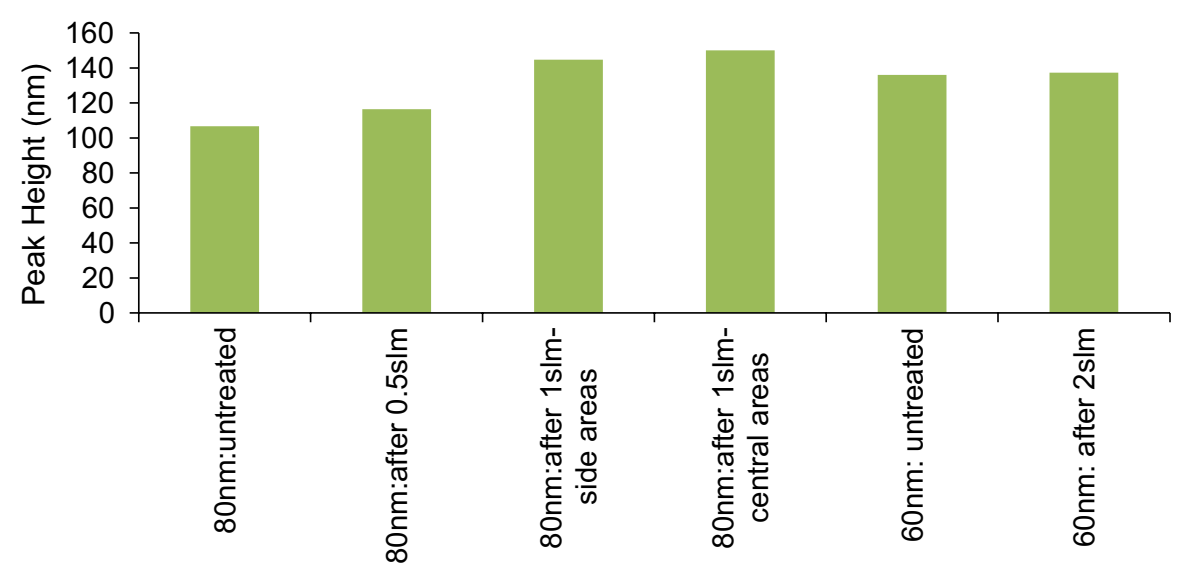

(c)

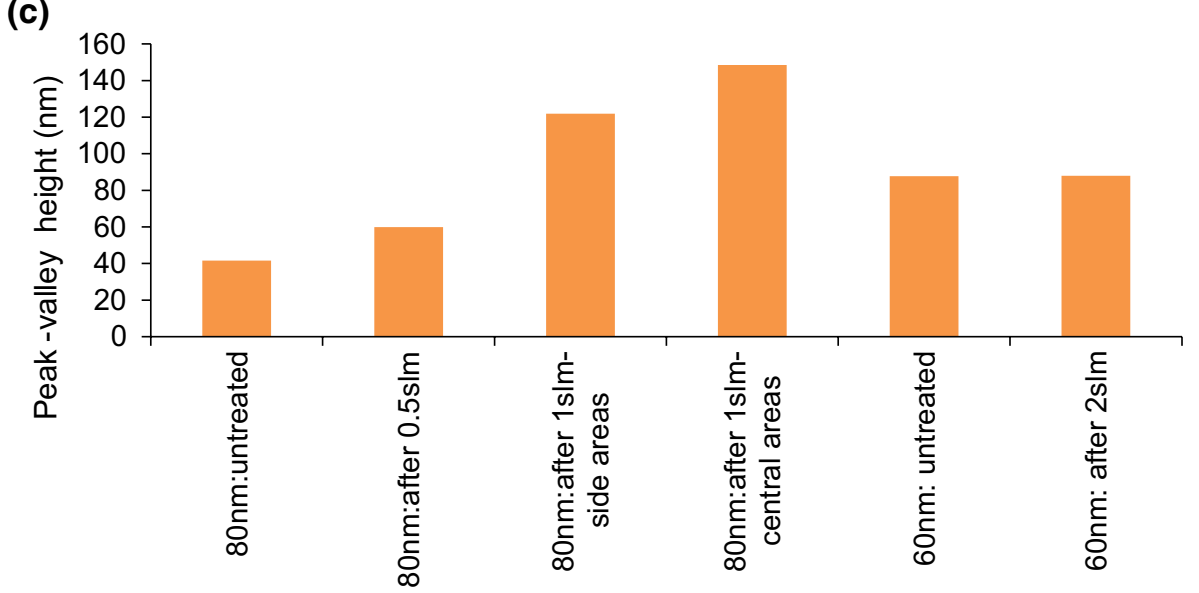

after plasma treatment with flow rate of 1 SLM (Fig. 9a). However, increasing gas flow rate to 2 SLM introduced insignificant changes in the values of $S_{v}, S_{p}$ and $S_{y}$.

The distance difference between the two highest peaks $\left(S_{m m}\right)$ was affected by both plasma treatment of 1 SLM and 2 SLM, as shown in Fig. 10a. From the distance difference between the two deepest valleys $\left(S_{v v}\right)$ view point, Fig. 10b illustrates that treated sample with gas flow rate of 1SLM increased $S_{v v}$ drastically up to $2500 \mathrm{~nm}$ which is in agreement with results obtained for both AFM image (Fig. 6c) and the peak valley height (Fig. 9a). In fact, plasma exposure with gas flow rate of 1 SLM causes further increase in the distance between the two deepest valleys $\left(S_{v v}\right)$ in the central area of Ag sample by making deeper valleys in the side areas and filling the valleys in the center. 
Fig. 10 Measurements of a distance difference between the two highest peaks $\left(S_{m m}\right)$, and $\mathbf{b}$ distance difference between the two lowest valleys $\left(S_{v v}\right)$ for the untreated and treated $\mathrm{Ag}$ thin films with different gas flow rates (0.5 SLM, 1 SLM, 2 SLM) for treatment time of $2 \mathrm{~min}$ (a)

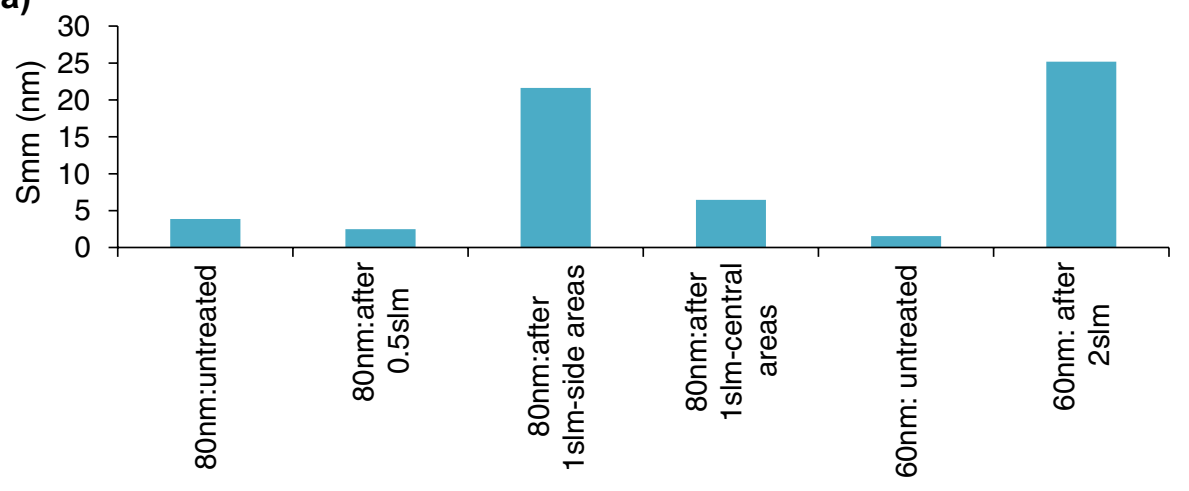

(b)

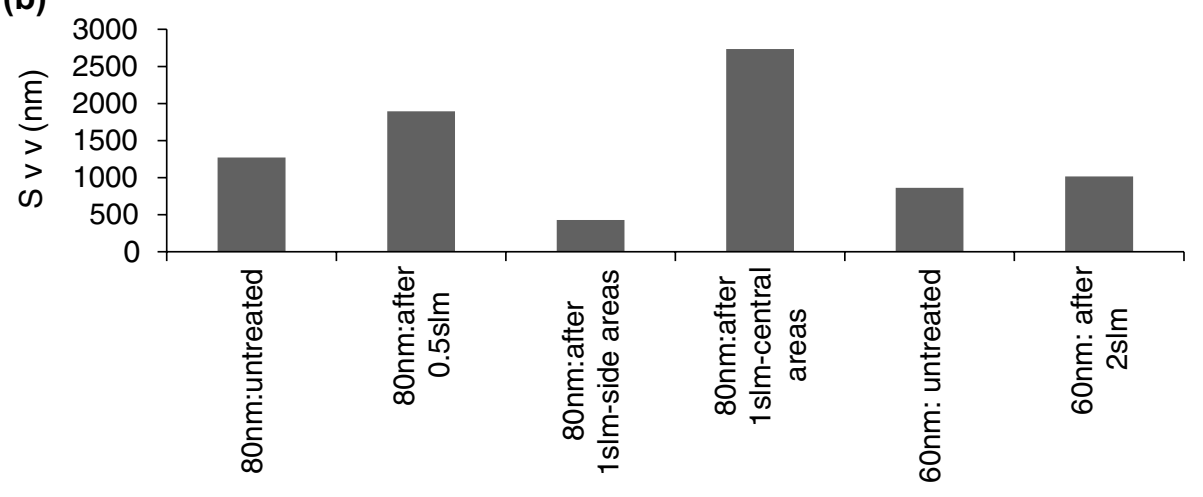

As a result, the Ar jet plasma treatment in gas flow rate 1 SLM seems to be more efficient in increasing the grain size, especially peak height of Ag NPs, after 2-min plasma exposure. This can be related to the emergence of radiations emitted from some energetic species in the plasma radiation which are excited only at gas flow rate of 1 SLM under the considered experimental conditions in Table 1. Thus, 1 SLM can be assumed as critical flow rate of the working gas in this experiment compared to the other examined gas flow rates (0.5 SLM and 2 SLM).

\section{Analytical study of Ag grains before and after perpendicular plasma jet processing under different gas flow rates}

To investigate how grain size and surface morphology of $\mathrm{Ag}$ thin films are affected by the perpendicular plasma exposure, 1D AFM profiles of samples were analyzed and measured by XY Extract Graph Digitizer v5.1 and Origin Pro v8.6 software in this section. Using the analytical method described in "Details of analytical method for study of surface morphology (grain size)" section, the grains specified by arrows in the 1D AFM profiles of untreated and treated Ag samples (Fig. 11) were measured and the corresponding results for height, area, and FWHM of grains are shown, respectively, in Fig. 13a-c. The errors reported by the Origin Pro software which are involved with the approximation are shown as error bars in Fig. 13. Please note that the approximated grains obtained from XY Extract Graph Digitizer and Origin Pro software for the untreated and treated Ag thin films are also displayed in Fig. 12.

Indeed, to analyze clearly the results obtained from XY Extract Graph Digitizer and Origin Pro software (see Fig. 12) for evaluation of peak height, FWHM, and area of grains specified in Fig. 11, the corresponding values are plotted in Fig. 13.

As can be seen in Figs. 12 and 13, no significant changes in the height, area, and full width at half maximum of grains with gas flow rate of $0.5 \mathrm{SLM}$ (the lowest flow of working gas) were detected in the treated sample. However, with further increasing of gas flow rate to 1 SLM and 2 SLM, the peak height of Ag grains enhanced up to $22.78 \mathrm{~nm}$ (almost 7 times higher than the untreated sample) and $20.28 \mathrm{~nm}$ (about 20 times higher than the untreated sample), respectively. In addition, as shown in Fig. 13b, the area of specified grains increased up to $4.57 \mathrm{~nm}$ for gas flow rate of 1 SLM (approximately 18 times wider than the untreated sample) and up to $3.51 \mathrm{~nm}$ for gas flow rate of 2 SLM (almost 29 times wider than the untreated sample). From the FWHM point of view, the value of $0.24 \mu \mathrm{m}$ was obtained for gas flow rate of 1 SLM (3.5 times greater than the untreated sample), and with further increasing flow rate to 2 SLM, as presented in Fig. 12, the FWHM was enhanced (0.14) about 2 times greater than the untreated sample. As a consequence, Ar plasma exposure with flow rates of 1 SLM and 2 SLM 
Fig. 11 1D AFM profiles of Ag samples with thickness of $80 \mathrm{~nm}$ a untreated, treated with gas flow rate of b 0.5 SLM, $\mathbf{c}$ 1 SLM, and with thickness of $60 \mathrm{~nm}$ d untreated, e treated with gas flow rate of 2 SLM
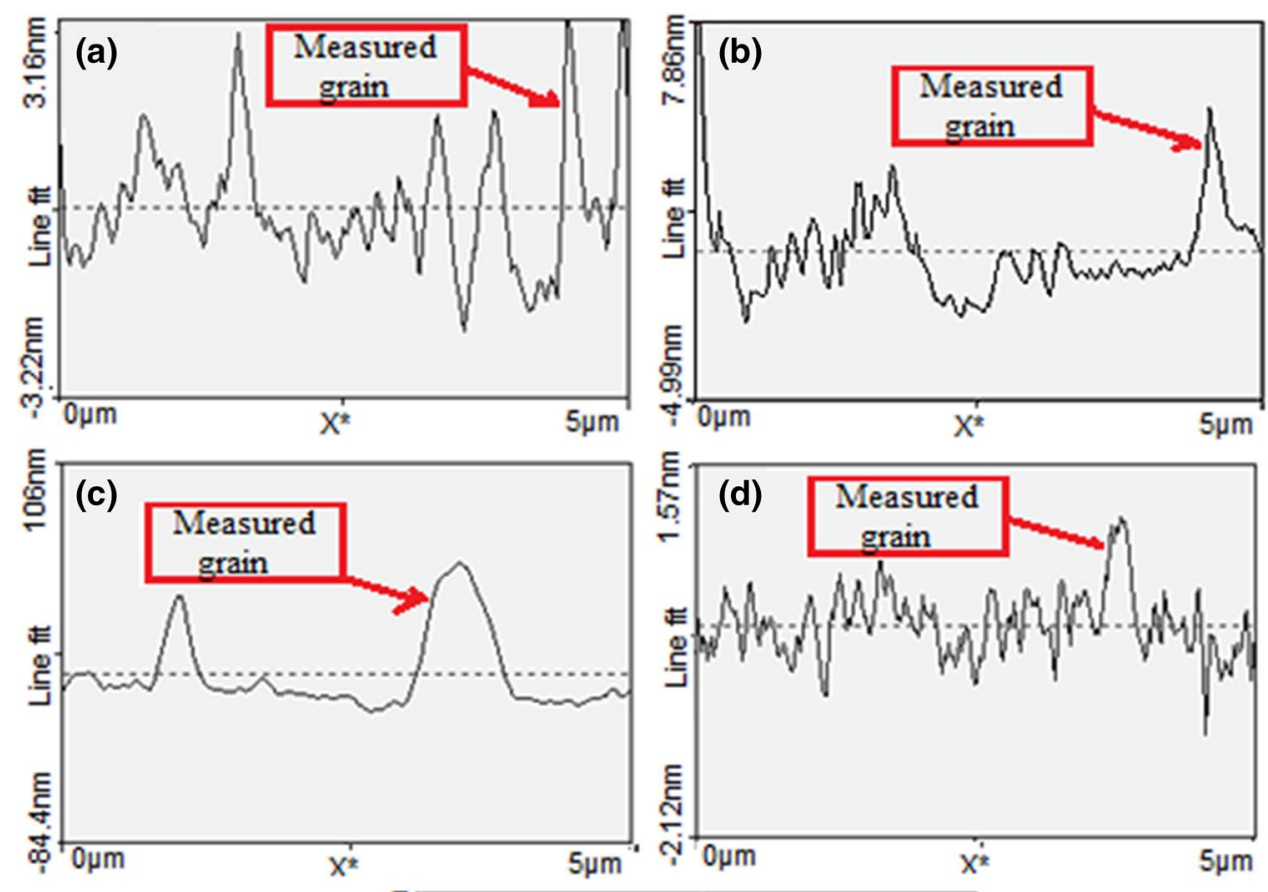

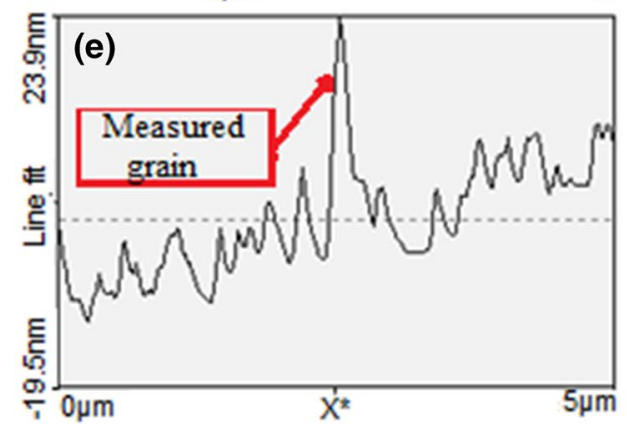

seems to be more efficient in the enhancement of height and area of grains compared to flow of 0.5 SLM. Also, gas flow rate of 1 SLM plays an important role in the increment of FWHM in treated Ag sample with thickness of $80 \mathrm{~nm}$; however, height and area of grains in the treated sample with thickness of $60 \mathrm{~nm}$ were affected remarkably by gas flow rate of 2 SLM. Moreover, the values of peak height and area of grains obtained from 1D AFM profiles in this section using XY Extract Graph Digitizer v5.1 and Origin Pro v8.6 software are in good agreement with the results of 2D and 3D AFM images achieved by Nanosurf Mobile S software and shown in Figs. 6 and 7, respectively.

\section{Influences of different non-perpendicular jet plasma processing $\left(30^{\circ}\right.$ and $\left.60^{\circ}\right)$ on the surface morphology and optical property of $\mathrm{Ag}$ thin films}

In this step, the influence of plasma exposure of Ar jet plasma with angles of $30^{\circ}$ and $60^{\circ}$ on the surface morphology and optical property of $\mathrm{Ag}$ samples with thicknesses of $80 \mathrm{~nm}$ and $100 \mathrm{~nm}$ are investigated under conditions described in "Details of plasma processing for non-perpendicular APPJ" section and Table 2. The purpose of employing non-perpendicular incidence angles of APPJ in this section was to show the relationship between incidence angle of plasma exposure and surface morphology, resulting in variation in the absorption spectra.

Please note that the employed Ag sample with thickness of $80 \mathrm{~nm}$ in this section was treated by Ar jet plasma perpendicular to surface for $2 \mathrm{~min}$ in the previous step ("Effects of different gas flow rates (0.5 SLM, 1 SLM, and 2 SLM) on the surface morphology of Ag thin films" section). In addition, the gas flow rate was assumed to be 1 SLM, which in the earlier section was found to be more effective on the surface morphology. Four images of plasma processing of Ag sample with thickness $80 \mathrm{~nm}$ are presented in Fig. 14. The 2D and 3D AFM images of Ag sample for the (a) untreated, treated with (b) perpendicular jet plasma and (c) with plasma exposure of $60^{\circ}$ are shown in Fig. 15.

It can be seen from Fig. 15 that in comparison with Fig. 6, the grain size grows approximately with the same 
Fig. 12 Approximated grains obtained from 1D AFM profiles related to Ag samples with thickness of $80 \mathrm{~nm}$ a untreated, treated with gas flow rate of $\mathbf{b}$ 0.5 SLM, c 1 SLM, and with thickness of $60 \mathrm{~nm}$ d untreated, e treated with gas flow rate of 2 SLM using XY Extract Graph Digitizer (digitized data) and Origin Pro (Gauss Amp Fit) software
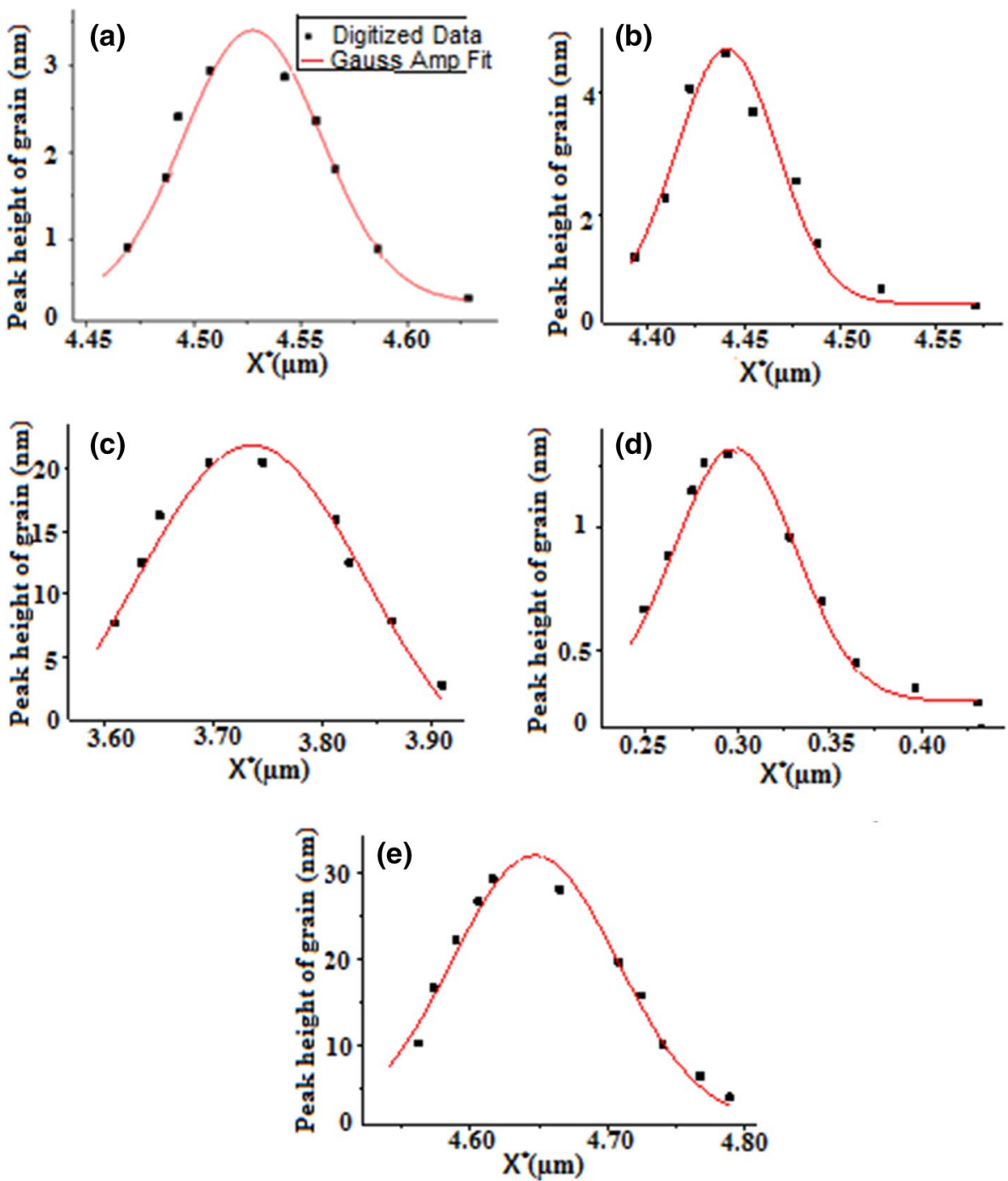

uniformity on the surface after the plasma treatment with incidence angle of $60^{\circ}$. Indeed, jet plasma with non-perpendicular direction seems to play an important role in the improvement in surface morphology, resulting in the reduction in not only valley depth but also peak height (see Fig. 15b, c). Based on this finding, the RMS of Ag sample as shown in Fig. 16 was increased in comparison with the treated sample with perpendicular jet plasma. However, this increment is not so significant. With respect to Fig. $17 \mathrm{c}$, it can be concluded that jet plasma with incidence angle of $60^{\circ}$ increased the value of peak valley height $\left(S_{y}\right)$ up to $176 \mathrm{~nm}$ which is almost $26 \mathrm{~nm}$ greater than the perpendicular plasma exposure. Indeed, as shown in Fig. 17a, b, the increment of the valley depth (almost $20 \mathrm{~nm}$ ) and the noticeable enhancement of peak height (about $46 \mathrm{~nm}$ ) led to a surface with more value of $S_{y}$. This can be related to the fact that plasma radiation with incidence angle of $60^{\circ}$ makes the grains in Ag sample (Fig. 15c) with more uniformity compared to the grains in the perpendicular treated sample (Fig. 15b). Also, this plasma exposure removes the Ag NPs and puts these NPs into the valleys; hence, not only the highest peaks but also the lowest valleys in Fig. 15b were disappeared. Moreover, shape of grains changed from round to plate-like as the non-perpendicular treatment was employed. Therefore, surface processing with incidence angle of $60^{\circ}$ promotes an improvement in surface morphology.

From Fig. 18a, b, it is seen that after jet treatment with angle of $60^{\circ}$, the distance difference between not only the two highest peaks $\left(S_{m m}\right)$ but also the two lowest pixels (valleys) $\left(S_{v v}\right)$ was reduced about $3 \mathrm{~nm}$ and $470 \mathrm{~nm}$, respectively, which are in agreement with the results obtained for AFM images in Fig. 15c as well as in Fig. 17. It can be due to the fact that plasma exposure with angle of $60^{\circ}$ decreased height of the highest grains and put these Ag NPs into the lowest valleys in their surroundings. This led to a surface of $\mathrm{Ag}$ thin film with more uniformity than the surface treated only with perpendicular jet plasma. 
Fig. 13 a Peak height, $\mathbf{b}$ area, and $\mathbf{c}$ FWHM of grains for the untreated and treated $\mathrm{Ag} \mathrm{sam}$ ples with different gas flow rates (0.5 SLM, 1 SLM, 2 SLM) for treatment time of $2 \mathrm{~min}$
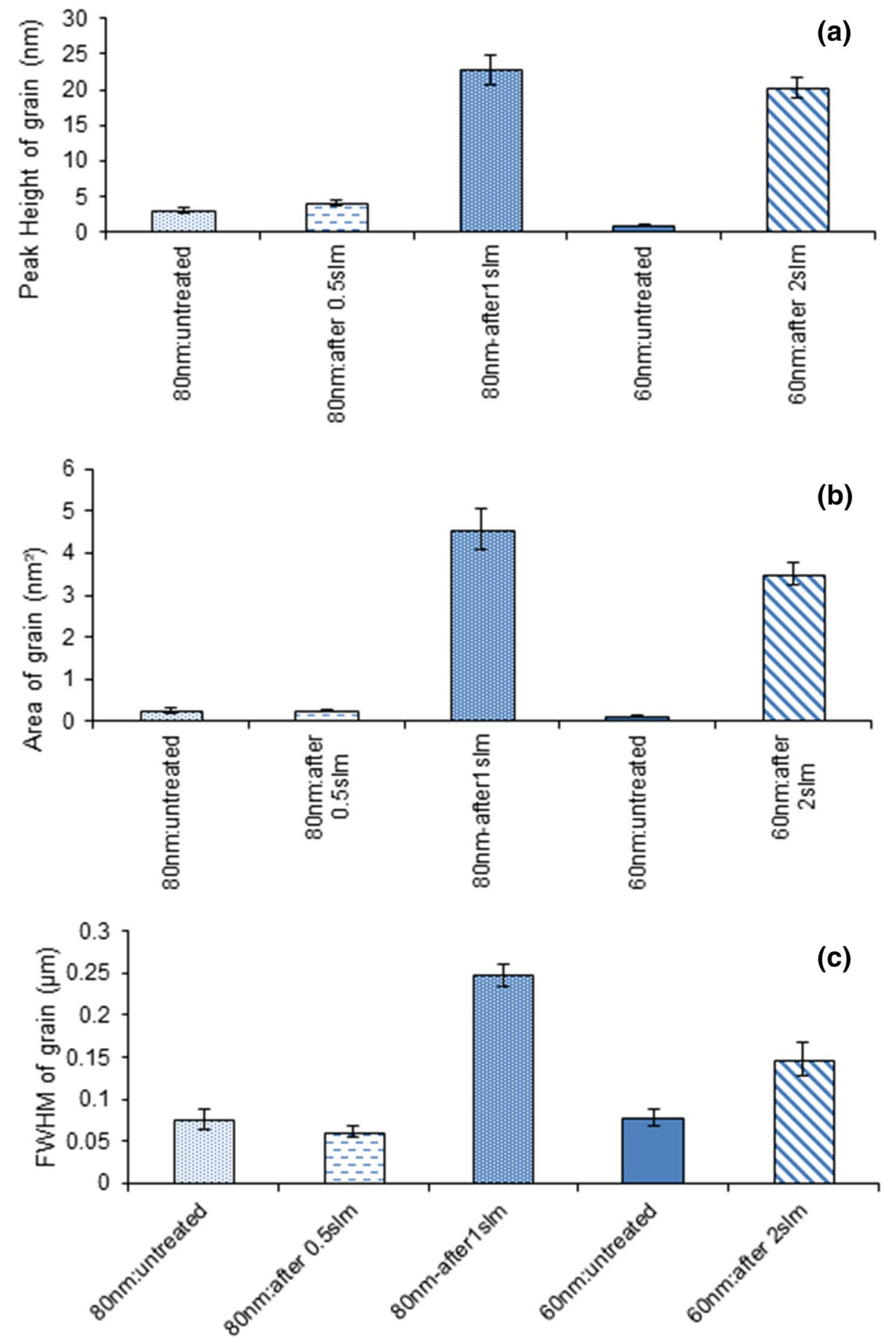

To show the influences of Ar jet plasma treatment with incidence angle of $60^{\circ}$ on the whole surface morphology of Ag thin film, 3D AFM images of the treated sample with three different windows are illustrated in Fig. 19.

To investigate how optical properties of $\mathrm{Ag}$ thin films are affected by the plasma exposure, Ag samples with thicknesses of $80 \mathrm{~nm}$ and $100 \mathrm{~nm}$ were treated, respectively, for $2 \mathrm{~min}$ and $1.5 \mathrm{~min}$ using non-perpendicular incidence angles of Ar jet plasma $\left(30^{\circ}\right.$ and $\left.60^{\circ}\right)$. The treatment time for $\mathrm{Ag}$ sample with thickness of $100 \mathrm{~nm}$ was decreased to $1.5 \mathrm{~min}$ because of the appearance of variations in the color of $\mathrm{Ag}$ coating of sample as the surface processing with angle of $30^{\circ}$ was carried out.

Figure 20a and $\mathrm{b}$ illustrates the absorbance as a function of wavelength (190-1100 nm) for Ag thin films with thicknesses of $80 \mathrm{~nm}$ and $100 \mathrm{~nm}$, respectively. As shown in Fig. 20a, UV-Vis absorption spectrometer illustrates that the maximum absorbance peak of $\mathrm{Ag}$ thin film with thickness 
Fig. 14 Images of surface processing of $\mathrm{Ag}$ thin film with thickness of $80 \mathrm{~nm}$ for total treatment time of 2 min under plasma exposure with incidence angle of $60^{\circ}$
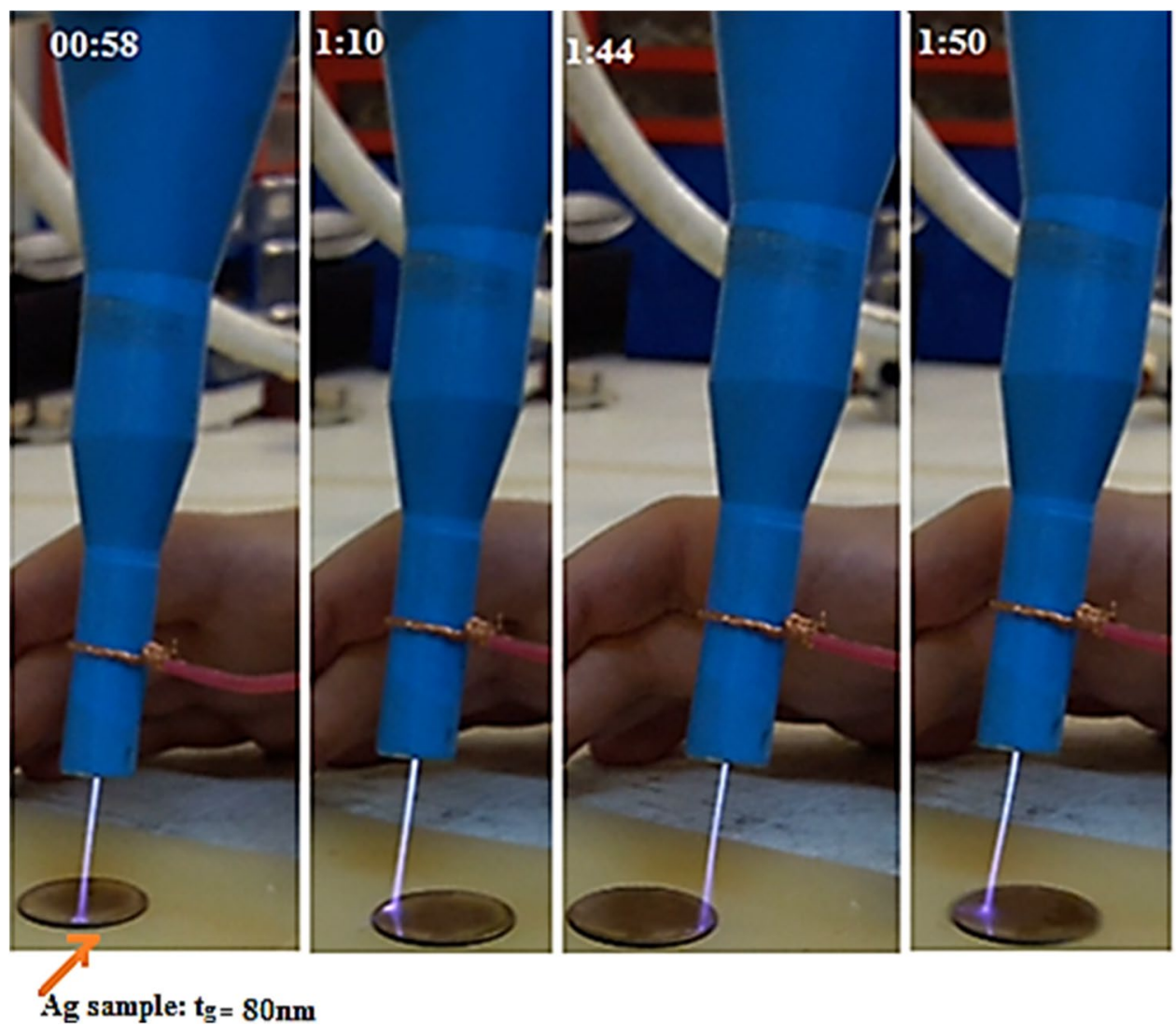

$80 \mathrm{~nm}$ was found to be red-shifted by $12 \mathrm{~nm}$ after sequential Ar plasma treatments (2-min plasma processing perpendicular to surface was followed by 2-min plasma treatment with non-perpendicular incidence angle of $60^{\circ}$ ). In addition, jet plasma treatment with angle of $60^{\circ}$ enhanced the value of absorbance from 42 to $55 \%$ (without considering the fluctuations). This observed increment in the peak of absorbance maximum is due to the fact that plasma exposure with angle of $60^{\circ}$ led to the improvement in surface morphology by making more uniformity in the distribution of Ag grains, and increasing the grain sizes, as shown in Figs. 15c and $17 \mathrm{a}, \mathrm{b}$. The emergence of fluctuations on the plot of treated Ag sample with plasma exposure of $60^{\circ}$ can be related to the reduction in distance difference between not only the two highest peaks $\left(S_{m m}\right)$ but also the two lowest valleys $\left(S_{v v}\right)$ after surface processing, as shown in Fig. 18. Moreover, the employed Ar gas cylinder for plasma jet consists of 1.5 PPM $\mathrm{H}_{2} \mathrm{O}$, leading to small steam bubbles on the surface of treated Ag thin film which may result in the presence of such fluctuations on the absorbance plots after plasma treatments.

No further significant variations in the absorption spectra of Ag sample with thickness of $100 \mathrm{~nm}$ were detected after plasma treatment with incidence angle of $30^{\circ}$, as presented in Fig. 20b. This finding may be explained by the fact that sample with higher film thickness cannot express acceptable peak of the absorbance maximum (reflectance minimum)
[67]. To show how grain sizes and absorption spectra are influenced by plasma processing with angle of $60^{\circ}$, the corresponding grains in the $1 \mathrm{D}$ AFM profiles of $\mathrm{Ag}$ sample with thickness of $80 \mathrm{~nm}$ were analyzed and measured using XY Extract Graph Digitizer v5.1 and Origin Pro v8.6 software in the following section.

\section{Analytical study of Ag grains before and after non-perpendicular $\left(60^{\circ}\right)$ plasma jet processing}

Since it is reported that the size and shape of nano-particles can affect absorption spectra [60-62], the peak height, area, and FWHM of gains in the treated Ag sample with thickness of $80 \mathrm{~nm}$ were analyzed and measured by XY Extract Graph Digitizer v5.1 and Origin Pro v8.6 software and the results are shown in Figs. 21 and 22, respectively. Also, the errors reported by the Origin Pro software which are involved with the approximation are shown as error bars in Fig. 22.

From Fig. 22, it can be concluded that after plasma treatment with incidence angle of $60^{\circ}$, the height, area, and FWHM of grains increased remarkably up to $133.88 \mathrm{~nm}$ (about 44 times higher than untreated sample), $68.22 \mathrm{~nm}$ (about 136 times greater than untreated sample), and $0.7 \mu \mathrm{m}$ (almost 10 times wider than untreated sample), respectively. Compared to the treated sample 
Fig. 15 2D and 3D AFM images of $\mathrm{Ag}$ thin film $(80 \mathrm{~nm})$ a untreated, and after $\mathbf{b}$ perpendicular Ar jet plasma c Ar jet plasma with incidence angle of $60^{\circ}$ with treatment time of 2 min and for gas flow rate of 1 SLM

Fig. 16 RMS measurements for the untreated and treated Ag thin films with different incidence angles, $60^{\circ}$ and $90^{\circ}$ for gas flow rate of 1 SLM and treatment time of $2 \mathrm{~min}$

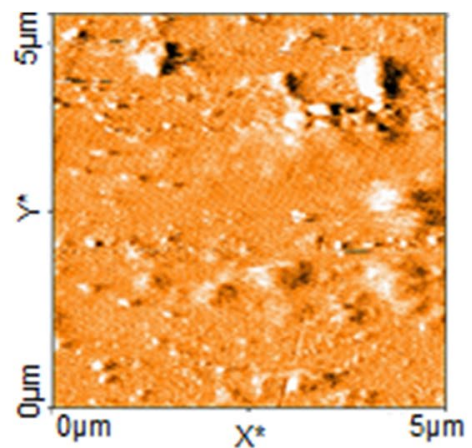

(a)

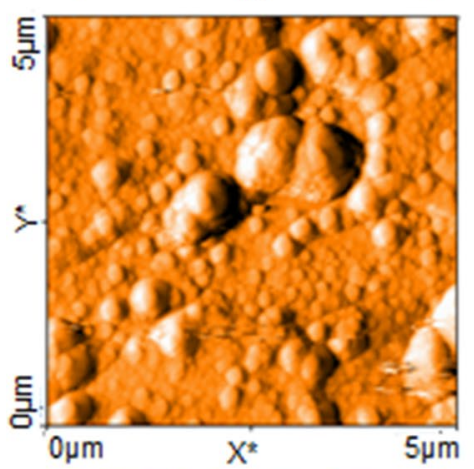

(b)
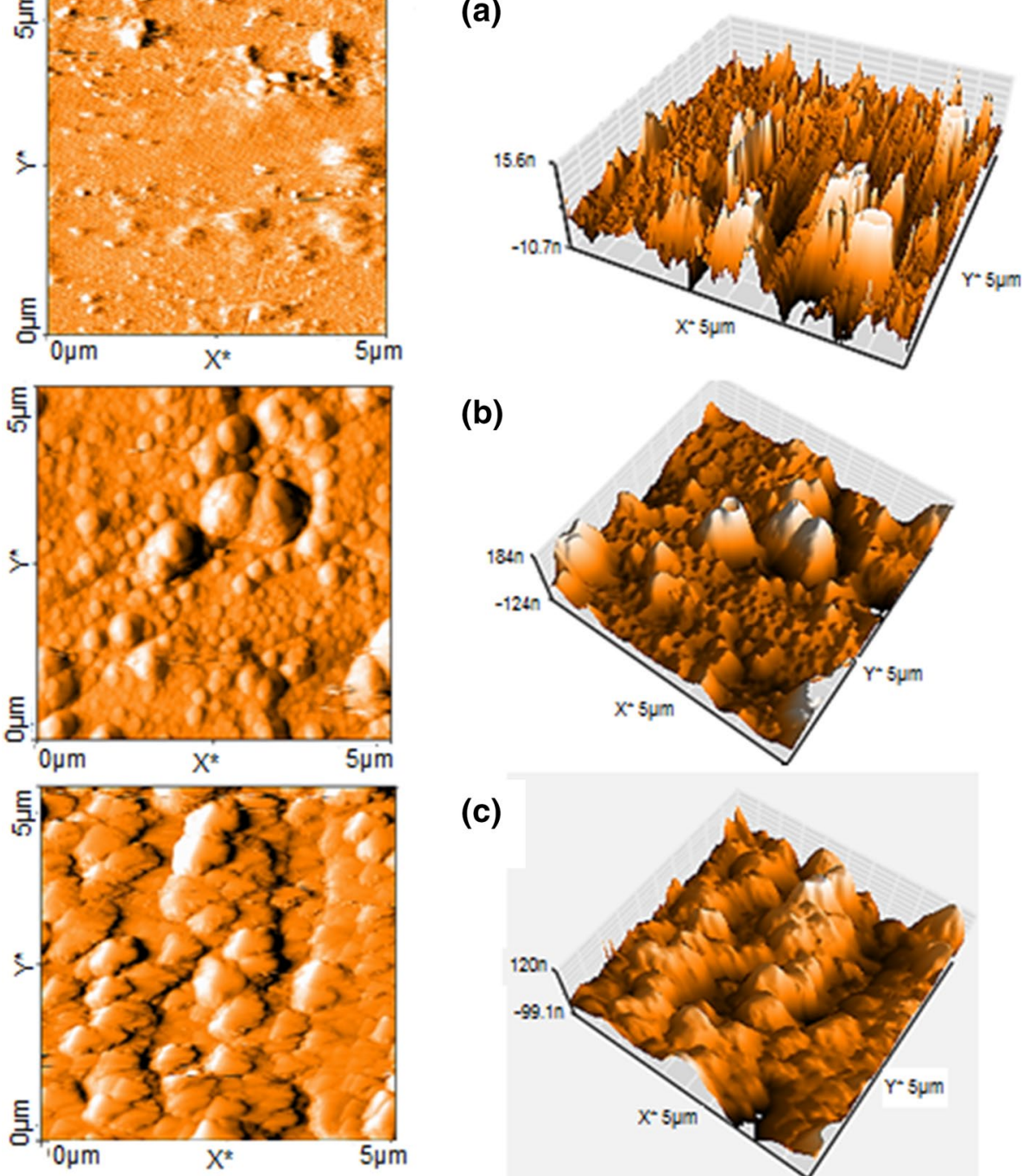

(c)

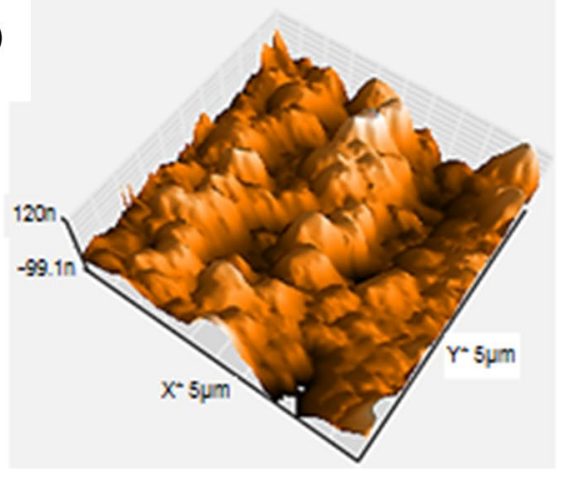

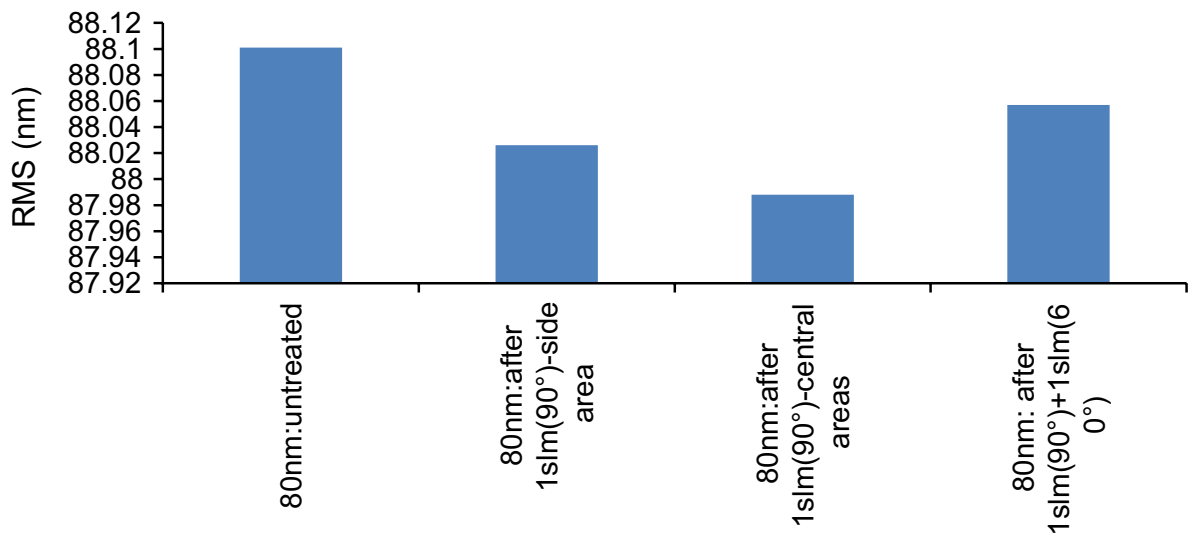

only with incidence angle of $60^{\circ}$, the initial values of height $(22.78 \mathrm{~nm})$, area $(4.6 \mathrm{~nm})$, and FWHM $(0.25 \mu \mathrm{m})$ enhanced, respectively, almost 7, 18, and 3 times greater than the treated surface with jet plasma angle of $90^{\circ}$. Furthermore, perpendicular plasma exposure to the surface increased the height and area of grains approximately 7 and 18 times greater than the untreated sample. However, for FWHM, the same increment can be seen after perpendicular treatment. As a result, a sequential jet plasma treatment (1SLM treatment with angle of $90^{\circ}$ was followed by 
Fig. 17 Measurements of a valley depth, b peak height, and $\mathbf{c}$ peak valley height for the untreated and treated $\mathrm{Ag}$ thin films with different incidence angles, $60^{\circ}$ and $90^{\circ}$ for gas flow rate of 1 SLM and treatment time of $2 \mathrm{~min}$ (a)

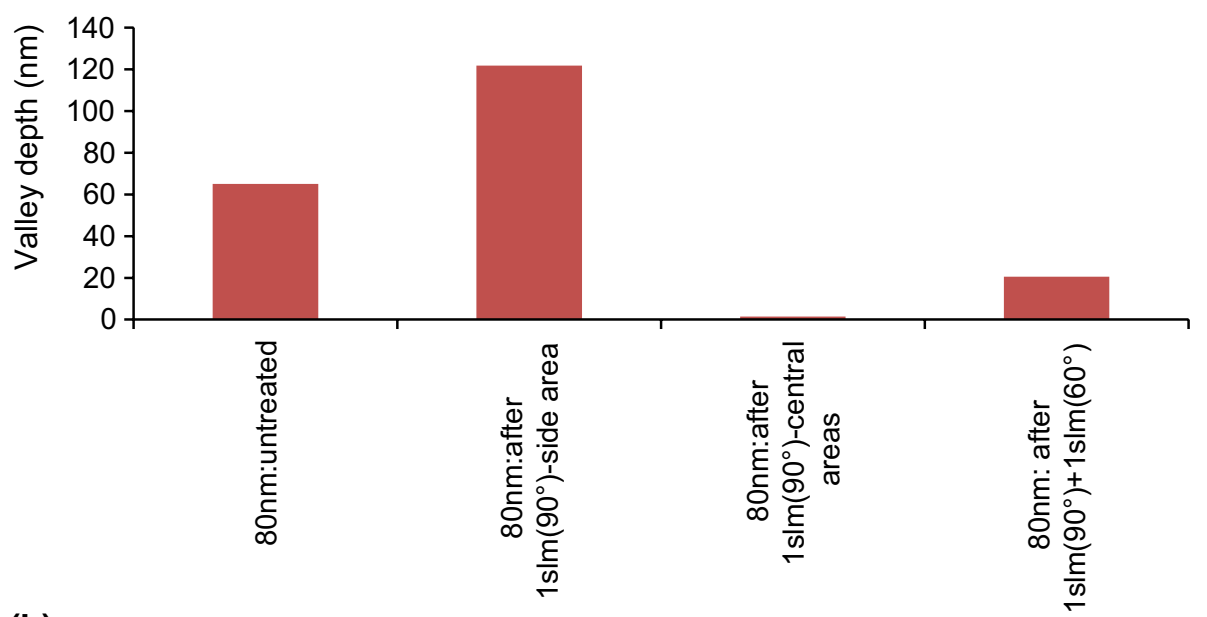

(b)

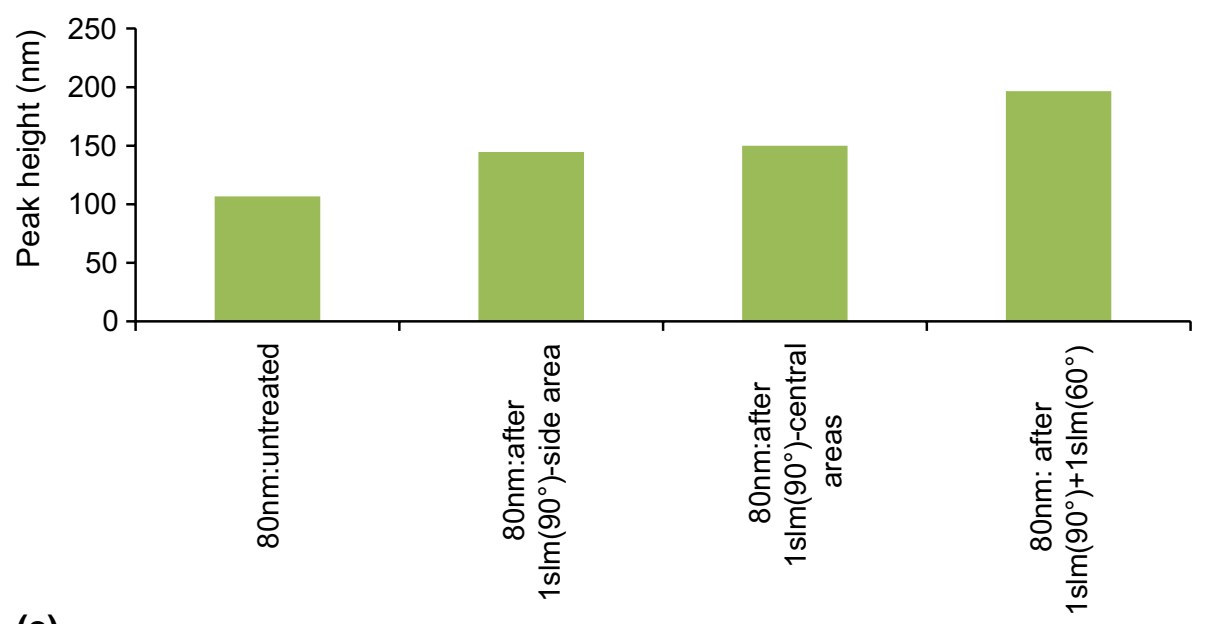

(c)

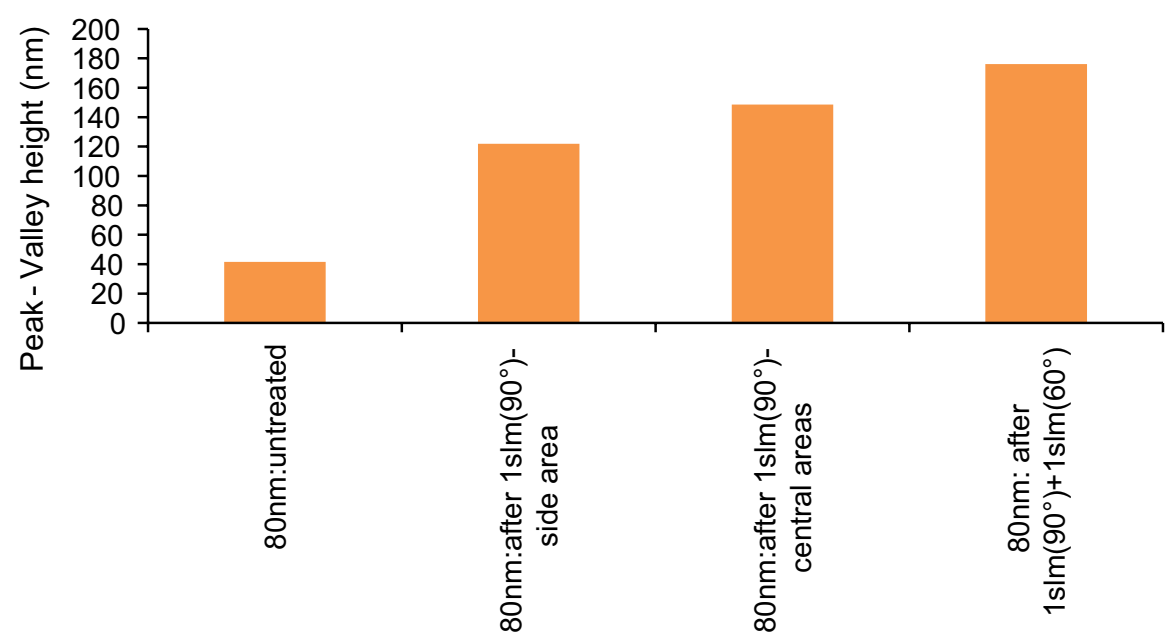

processing with the same gas flow rate and angle of $60^{\circ}$ ) seems to be more effective in enhancing the grain size, especially the height and area of grains.

\section{Conclusion}

In this study, $\mathrm{Ag}$ thin films were treated with different gas flow rates (0.5 SLM, 1 SLM, and 2 SLM) using perpendicular Ar jet plasma as well as with non-perpendicular 
Fig. 18 Measurements of a distance difference between the two highest peaks $\left(S_{m m}\right)$, and $\mathbf{b}$ distance difference between the two lowest valleys $\left(S_{v v}\right)$ for the untreated and treated $\mathrm{Ag}$ thin films $(80 \mathrm{~nm})$ with different incidence angles, $60^{\circ}$ and $90^{\circ}$ for gas flow rate of 1 SLM and treatment time of 2 min

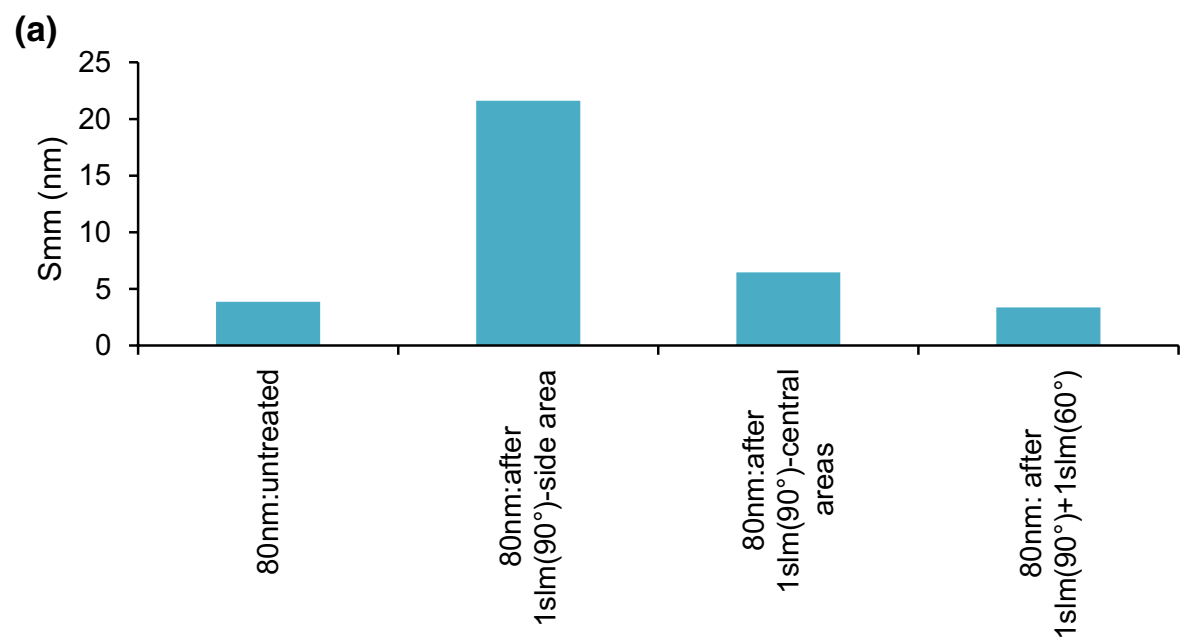

(b)

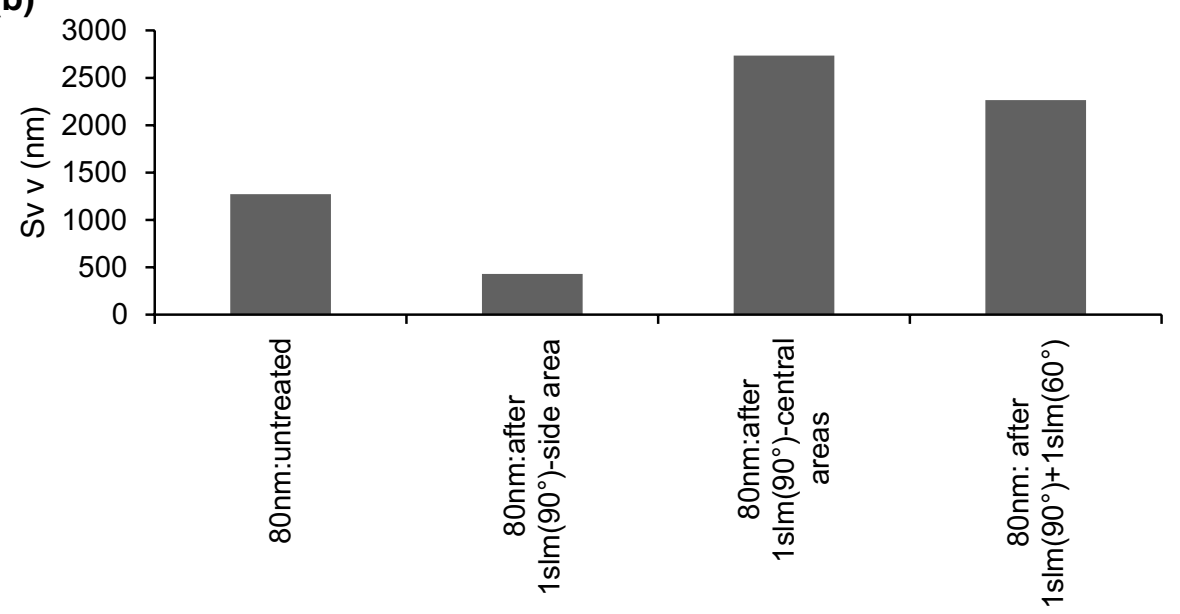

(a)

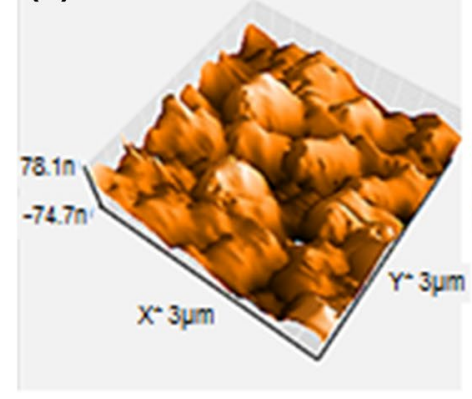

(b)

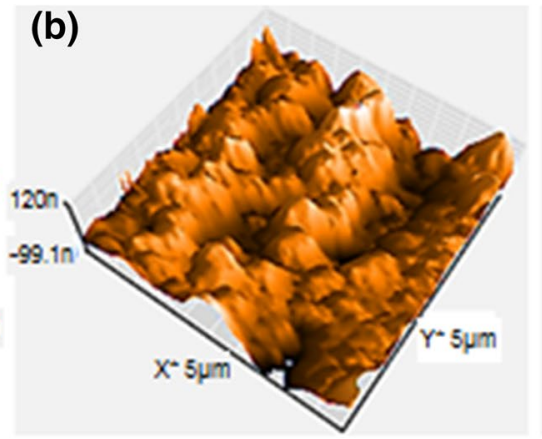

(c)

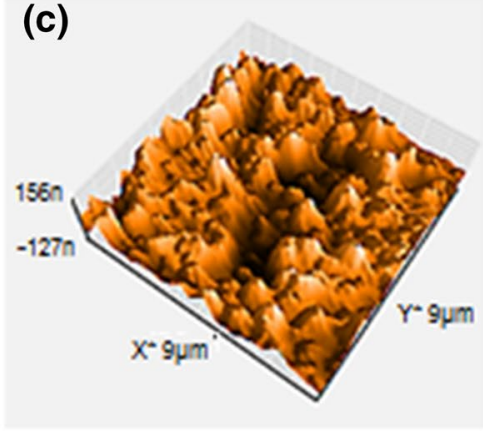

Fig. 19 3D AFM images of Ag thin film $(80 \mathrm{~nm})$ treated with Ar plasma jet with incidence angle of $60^{\circ}$ and treatment time of 2 min for different AFM windows a $3 \mu \mathrm{m} \times 3 \mu \mathrm{m}, \mathbf{b} 5 \mu \mathrm{m} \times 5 \mu \mathrm{m}, \mathbf{c} 9 \mu \mathrm{m} \times 9 \mu \mathrm{m}$

incidence angle of jet plasma $\left(30^{\circ}\right.$ and $\left.60^{\circ}\right)$ and gas flow rate of 1 SLM at atmospheric pressure. The surface morphology and optical property of the untreated and treated Ag samples were characterized using AFM and spectrophotometer. To investigate the influences of plasma exposure with different gas flow rates and various incidence angles on the surface morphology, the grains were analyzed and approximated using a Gaussian function by XY Extract Graph Digitizer v5.1 and Origin Pro v8.6 software. The analytical results obtained by XY Extract Graph Digitizer and Origin Pro software for grain sizes are in good agreement with the experimental evaluations achieved for surface morphology utilizing Nanosurf Mobile S software. The AFM studies of Ag thin films on 
Fig. 20 Variations of absorbance $(\mathrm{ABS})$ power of $\mathrm{Ag}$ thin films ( $80 \mathrm{~nm}$ and $100 \mathrm{~nm}$ ) for different angles of jet plasma exposure a $60^{\circ}$ : treatment time of 2 min and $\mathbf{b} 30^{\circ}$ : treatment time of $1.5 \mathrm{~min}$
Fig. 21 Ag sample with thickness of $80 \mathrm{~nm}$ treated with gas flow rate of 1 SLM and incidence angle of $60^{\circ}$ a $1 \mathrm{D}$ AFM profiles and $\mathbf{b}$ approximated grain using XY Extract Graph Digitizer (digitized data) and Origin Pro (Gauss Amp Fit) software

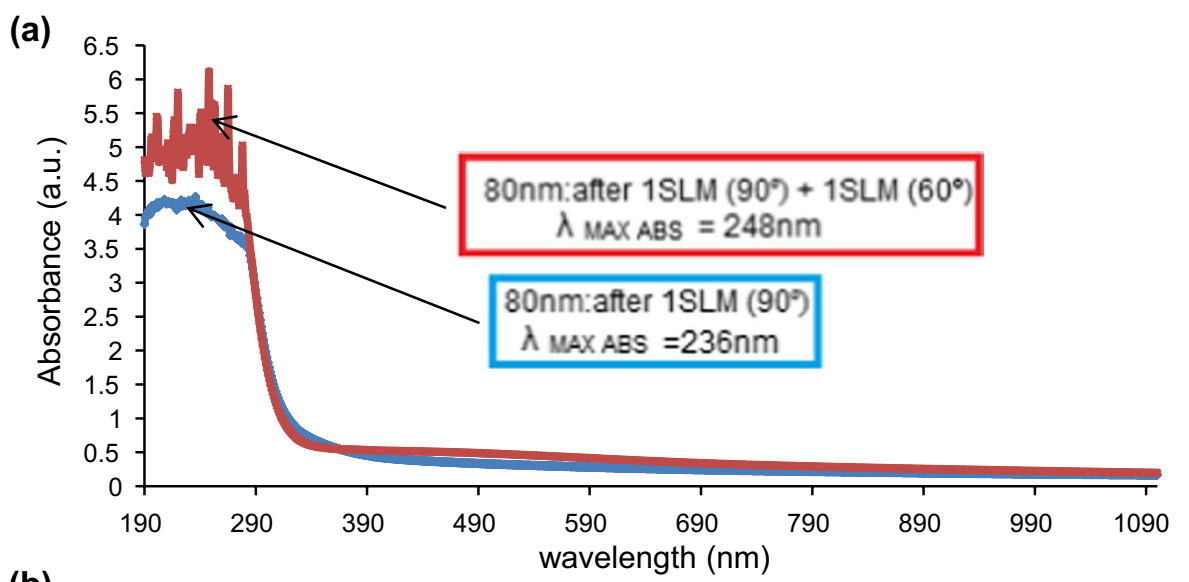

(b)

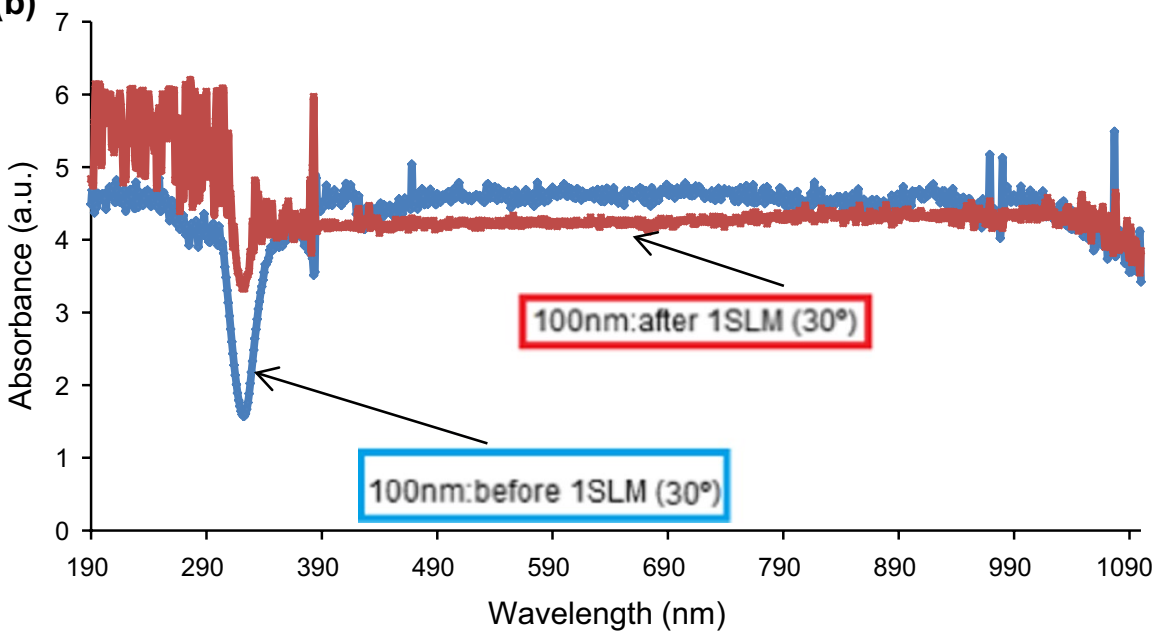

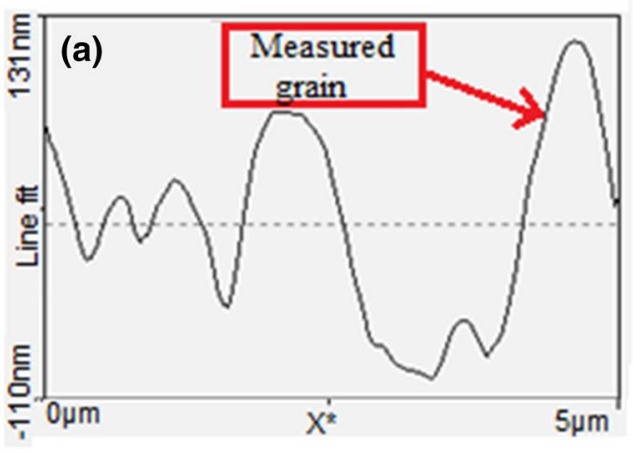

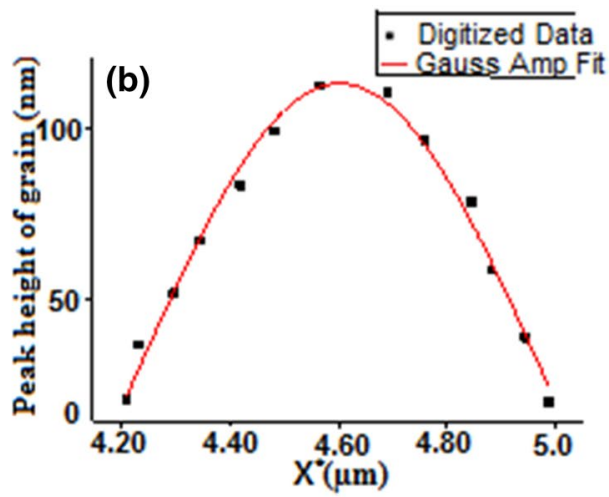

glass show that both jet plasma treatments (different gas flow rates or non-perpendicular plasma exposure) result in no or little variations of the RMS measurements of the treated Ag samples. However, peak height, valley depth, distance difference between the two deepest valleys and highest peaks were increased remarkably after treatment with gas flow rate of 1 SLM. Thus, the Ar jet plasma treatment in gas flow rate of 1 SLM seems to be more efficient in increasing the grain size, especially peak height of $\mathrm{Ag}$ NPs, after 2-min plasma exposure. This can be related to the emergence of radiations emitted from some energetic species in the plasma radiation which can be detected only at the flow rate of 1 SLM. Therefore, this gas flow rate can be assumed as critical gas flow rate of Ar jet plasma employed in this experiment. In addition, the findings of UV-Vis absorption spectrometer show that the position of maximum absorbance peak of Ag thin film with thickness $80 \mathrm{~nm}$ was found to be red-shifted by $12 \mathrm{~nm}$ and increased from 42 to $55 \%$ after sequential Ar plasma treatments, which is in good agreement with the results obtained 
Fig. 22 a Peak height, $\mathbf{b}$ area, and $\mathbf{c}$ FWHM of grains for the untreated and treated $\mathrm{Ag}$ thin films with different incidence angles, $60^{\circ}$ and $90^{\circ}$ for gas flow rate of 1 SLM and treatment time of $2 \mathrm{~min}$

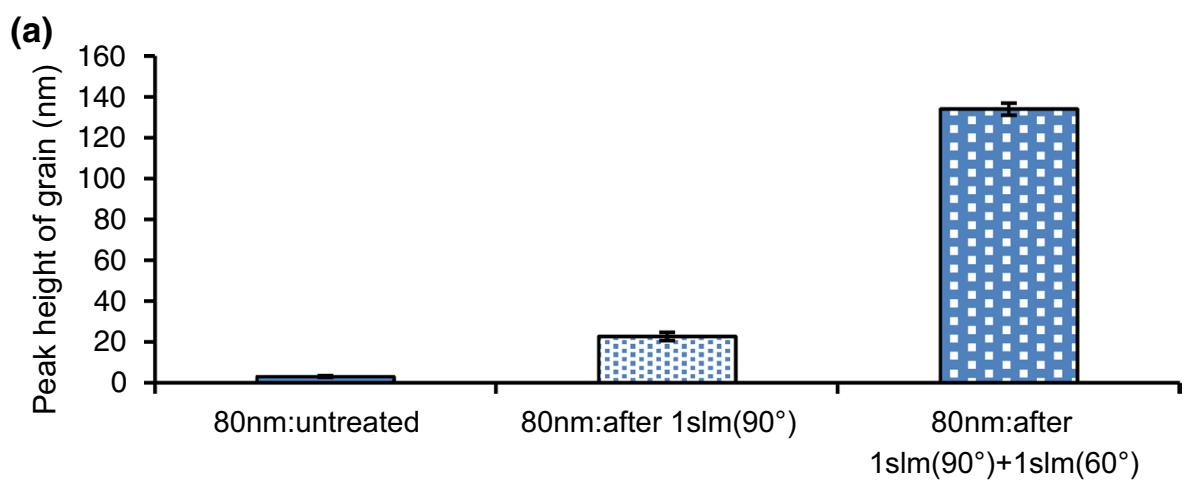

(b)

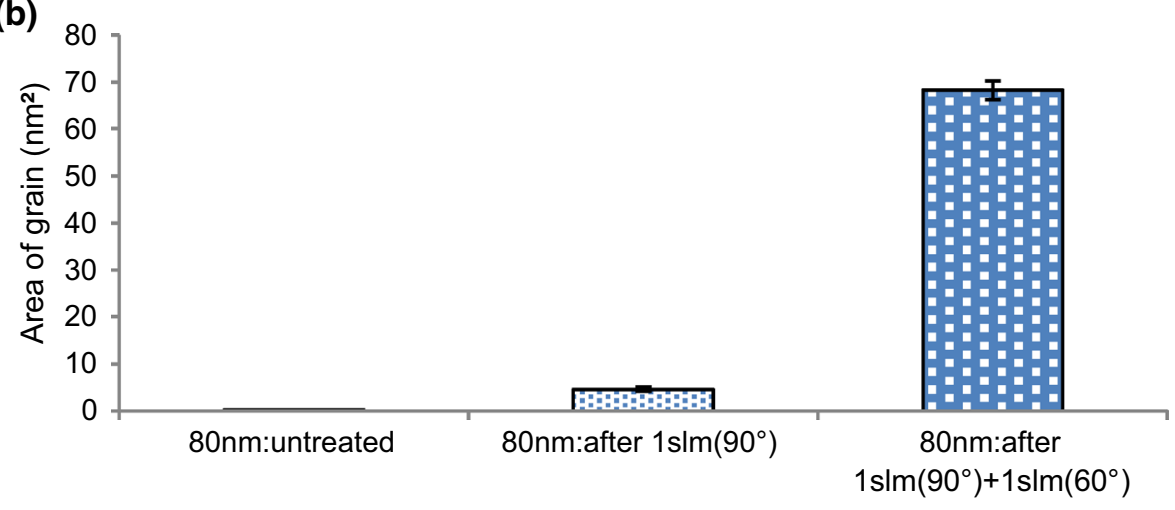

(c)

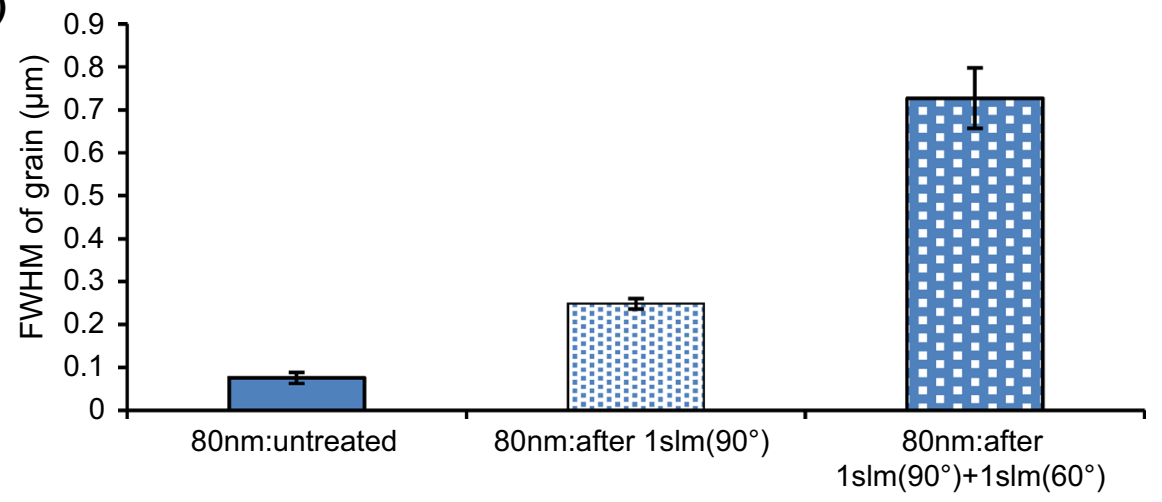

from the presented analytical method for evaluation of grain sizes. The Ar jet plasma treatment with angle of $60^{\circ}$ seems to be more effective in not only improvement in surface morphology but also enhancement of the absorbance maximum peak. This led to both the uniformity in distribution of Ag NPs and the enhancement of grain size (especially in the height and area of grains), resulting in the improvement in optical property of Ag sample, which can be useful in optical sensing applications. As a result, a sequential jet plasma treatment (1 SLM treatment with angle of $90^{\circ}$ was followed by processing with the same gas flow rate and angle of $60^{\circ}$ ) seems to be more effective in enhancing the grain size, resulting in the improvement in surface morphology.
Open Access This article is distributed under the terms of the Creative Commons Attribution 4.0 International License (http://creativeco mmons.org/licenses/by/4.0/), which permits unrestricted use, distribution, and reproduction in any medium, provided you give appropriate credit to the original author(s) and the source, provide a link to the Creative Commons license, and indicate if changes were made.

\section{References}

1. Cheng, X., Dong, P., Huang, Z., Zhang, Y., Chen, Y., Nie, X., Zhang, X.: Green synthesis of plasmonic Ag nanoparticles anchored $\mathrm{TiO}_{2}$ nanorod arrays using cold plasma for visible-lightdriven photocatalytic reduction of $\mathrm{CO}_{2}$. J. CO2 Util. (2017). https ://doi.org/10.1016/j.jcou.2017.04.009

2. De, M., Ghosh, P.S., Rotello, V.M.: Applications of nanoparticles in biology. Adv. Mater. (2008). https://doi.org/10.1002/ adma.200703183 
3. Kajani, A.A., Bordbar, A.K., Esfahani, S.H.Z., Khosropour, A.R., Razmjou, A.: Green synthesis of anisotropic silver nanoparticles with potent anticancer activity using Taxus baccata extract. RSC Adv. (2014). https://doi.org/10.1039/C4RA08758E

4. Wei, H., Eilers, H.: From silver nanoparticles to thin films: evolution of microstructure and electrical conduction. J. Phys. Chem. Solids (2009). https://doi.org/10.1016/j.jpcs.2008.11.012

5. Maroof, A., Hegazy, B.E.: Preparation and characterization of silver nanoparticles homogenous thin films. NRIAG J. Astron. Geophys. (2018). https://doi.org/10.1016/j.nrjag.2018.04.002

6. Zawadzka, K., Kisielewska, A., Piwonski, I., Kadziola, K., Felczak, A., Rozalska, S., Wronska, N., Lisowska, K.: Mechanisms of antibacterial activity and stability of silver nanoparticles grown on magnetron sputtered $\mathrm{TiO}_{2}$ coatings. Bull. Mater. Sci. (2016). https://doi.org/10.1007/s12034-015-1137-z

7. Liu, Y., Wang, X., Yang, F., Yang, X.: Excellent antimicrobial properties of mesoporous anatase $\mathrm{TiO}_{2}$ and $\mathrm{Ag} / \mathrm{TiO}{ }_{2}$ composite films. Microporous Mesoporous Mater. (2008). https://doi. org/10.1016/j.micromeso.2008.01.032

8. Nesterenko, D.V., Sekkat, Z.: Resolution estimation of the Au, Ag, $\mathrm{Cu}$, and $\mathrm{Al}$ single and double-layer surface plasmon sensors in the ultraviolet, visible, and infrared regions. Plasmonics (2013). https ://doi.org/10.1007/s11468-013-9575-1

9. Hottin, J., Wijaya, E., Hay, L., Maricot, S., Bouazaoui, M., Vilcot, J.P.: Comparison of gold and silver/gold bimetallic surface for highly sensitive near-infrared SPR sensor at $1550 \mathrm{~nm}$. Plasmonics (2013). https://doi.org/10.1007/s11468-012-9446-1

10. Michel, D., Xiao, F., Alameh, K.: Compact, flexible fiber-optic Surface Plasmon Resonance sensor with changeable sensor chips. Sens. Actuators B Chem. (2017). https://doi.org/10.1016/j. snb.2017.02.064

11. Hajipour, M.J., Fromm, K.M., Ashkarran, A.A., Aberasturi, D.J.D., Larramendi, I.R.D., Rojo, T., Serpooshan, V., Parak, W.J., Mahmoudi, M.: Antibacterial properties of nanoparticles. Trends Biotechnol. (2012). https://doi.org/10.1016/j.tibtech.2012.06.004

12. Rai, M., Yadav, A., Gade, A.: Silver nanoparticles as a new generation of antimicrobials. Biotechnol. Adv. (2009). https://doi. org/10.1016/j.biotechadv.2008.09.002

13. Prasad, T.N.V.K.V., Kambala, V.S.R., Naidu, R.: A critical review on biogenic silver nanoparticles and their antimicrobial activity. Curr. Nanosci. (2011). https://doi.org/10.2174/157341311796196 736

14. Kroger, R., Eizenberg, M.: Plasma induced microstructural, compositional, and resistivity changes in ultrathin chemical vapor deposited titanium nitride films. J. Appl. Phys. (2002). https:// doi.org/10.1063/1.1459750

15. Paproth, A., Wolter, K.J., Herzog, T., Zerna, T.: Influence of plasma treatment on the improvement of surface energy, 4th International Spring Seminar on Electronics Technology. Romania (2001). https://doi.org/10.1109/ISSE.2001.931005

16. Wolf, R., Sparavigna, A.C.: Role of plasma surface treatments on wetting and adhesion. Engineering (2010). https://doi. org/10.4236/eng.2010.26052

17. Wojcieszak, D., Poniedzialek, A., Mazur, M., Domaradzki, J.: Influence of plasma treatment on wettability and scratch resistance of Ag-coated polymer substrates. Mater. Sci. Pol. (2016). https://doi.org/10.1515/msp-2016-0058

18. Kondo, T., Watanabe, R., Shimoyama, Y., Shinohe, K., Kulinich, S.A., Iwamori, S.: Effect of reactive oxygen species generated with ultraviolet lamp and plasma on polyimide surface modification. Surf. Interface Anal. (2017). https://doi. org/10.1002/sia.6279

19. Hartl, H., Guo, Y., Ostrikov, K., Xian, Y., Zheng, J., Li, X., Smitha, K.E.F., Macleod, J.: Film formation from plasma-enabled surface-catalyzed dehalogenative coupling of a small organic molecule. RSC Adv. (2019). https://doi.org/10.1039/C8RA08920E
20. Zhang, C., Fang, Z., Yin, Y., Shao, T.: Plasma surface treatment of $\mathrm{Cu}$ by nanosecond-pulse diffuse discharges in atmospheric airs. Plasma Sci. Technol 1, 2-3 (2018). https://doi.org/10.1088/20586272/aa8c6e

21. Kostov, K.G., Hamia, Y.A.A.: Treatment of polycarbonate by dielectric barrier discharge (DBD) at atmospheric pressure. J. Phys: Conf. Ser. 511, 012075 (2014)

22. Nastuta, A.V., Rusu, G.B., Topala, I., Chiper, A.S., Pop, G.: Surface modifications of polymer induced by atmospheric DBD plasma in different configurations. J. Optoelectron. Adv. Mater. 10, 2038-2042 (2008)

23. Shaer, M.E., Mobasher, M., Elsebaei, A., Adel, F.: Polymers surface treatment by cold atmospheric plasma in air. In: Proceedings of 13th Arab International Conference on Polymer Science and Technology [ESPST- 2017] (2017)

24. Williams, D.F., Ewen Kellar, J.C., Jesson, D.A., Watts, J.F.: Surface analysis of 316 stainless steel treated with cold atmospheric plasma. Appl. Surf. Sci. (2017). https://doi.org/10.1016/j.apsus c.2017.01.150

25. Karki, S.B., Ayan, E.Y., Eisenmann, K.M., Ayan, H.: Miniature dielectric barrier discharge non-thermal plasma induces apoptosis in lung cancer cells and inhibits cell migration. Bio Med. Res. Int. (2017). https://doi.org/10.1155/2017/8058307

26. Deng, S., Ruan, R., Mok, C.K., Huang, G., Lin, X.: Inactivation of Escherichia coli on almonds using non thermal plasma. J. Food Sci. (2007). https://doi.org/10.1111/j.1750-3841.2007.00275.x

27. Arora, V., Nikhil, V., Suri, N.K., Arora, P.: Cold atmospheric plasma (CAP) in dentistry. Dentistry (2014). https://doi. org/10.4172/2161-1122.1000189

28. Pankaj, S.K., Wan, Z., Keener, K.M.: Effects of cold plasma on food quality. Foods (2018). https://doi.org/10.3390/foods7010004

29. Fanelli, F., Fracassi, F.: Atmospheric pressure non-equilibrium plasma jet technology: general features, specificities and applications in surface processing of materials. Surf. Coat. Technol. (2017). https://doi.org/10.1016/j.surfcoat.2017.05.027

30. Hosseinpour, M., Zendehnam, A.: Study of an argon dielectric barrier discharge reactor with atmospheric pressure for material treatment. J. Theor. Appl. Phys. (2018). https://doi.org/10.1007/ s40094-018-0316-x

31. Passaras, D.N.: Simulation of Atmospheric Pressure Plasma Jets with a Global Model. Master'S Thesis (2016)

32. Robert, E., Sarron, V., Darny, T., Riès, D., Dozias, S., Fontane, J., Joly, L., Pouvesle, J.M.: Rare gas flow structuration in plasma jet experiments. Plasma Sources Sci. Technol. (2014). https://doi. org/10.1088/0963-0252/23/1/012003

33. Qaisrani, M.H., Xian, Y., Li, C., Pei, X., Ghasemi, M., Lu, X.: Study on dynamics of the influence exerted by plasma on gas flow field in non-thermal atmospheric pressure plasma jet. Phys. Plasmas (2016). https://doi.org/10.1063/1.4954828

34. Sarron, V., Robert, E., Fontane, J., Darny, T., Riès, D., Dozias, S., Joly, L., Pouvesle, J.M.: Plasma plume length characterization. In: von Keudell, A., Winter, J., Böke, M., Schutz-von der Gathen, V. (eds.), Proceedings of the 19th International Symposium of Plasma Chemistry, Bochum, Germany (2009)

35. Xiong, Q., Lu, X., Ostrikov, K., Xiong, Z., Xian, Y., Zhou, F., Zou, C., Hu, J., Gong, W., Jiang, Z.: Length control of He atmospheric plasma jet plumes: effects of discharge parameters and ambient air. Phys. Plasmas (2009). https://doi.org/10.1063/1.3119212

36. Lu, X., Laroussi, M., Puech, V.: On atmospheric-pressure nonequilibrium plasma jets and plasma bullets. Plasma Sources Sci. Technol. (2012). https://doi.org/10.1088/0963-0252/21/3/034005

37. Kim, J.Y., Ballato, J., Kim, S.O.: Intense and energetic atmospheric pressure plasma jet arrays. Plasma Process. Polym. (2012). https://doi.org/10.1002/ppap.201100190

38. Zhang, C., Shao, T., Zhou, Y., Fang, Z., Yan, P., Yang, W.: Effect of $\mathrm{O}_{2}$ additive on spatial uniformity of atmospheric-pressure 
helium plasma jet array driven by microsecond-duration pulses. Appl. Phys. Lett. (2014). https://doi.org/10.1063/1.4887992

39. Wang, R., Sun, H., Zhu, W., Zhang, C., Zhang, S., Shao, T.: Uniformity optimization and dynamic studies of plasma jet array interaction in argon. Phys. Plasmas (2017). https://doi. org/10.1063/1.4998469

40. Wang, R., Xu, H., Zhao, Y., Zhu, W., Zhang, C., Shao, T.: SpatialTemporal evolution of a radial plasma jet array and its interaction with material. Plasma Chem. Plasma Process. (2019). https://doi. org/10.1007/s11090-018-9929-8

41. Dong, P., Fang, P., Cheng, X., Huang, Z., Xiao, Y., Zhang, X., Nie, $X .:$ Plasmon enhanced photocatalytic and antimicrobial activities of $\mathrm{Ag}-\mathrm{TiO}_{2}$ nanocomposites under visible light irradiation prepared by DBD cold plasma. Mater. Sci. Eng., C (2019). https ://doi.org/10.1016/j.msec.2018.11.005

42. Chandana, L., Ghosal, P., Shashidhar, T., Subrahmanyam, Ch.: Enhanced photocatalytic and antibacterial activity of plasmareduced silver nanoparticles. RSC Adv. (2018). https://doi. org/10.1039/c8ra03961e

43. Zhang, J., Di, L., Zhang, X.: Atmospheric-pressure cold plasma activating $\mathrm{Au} / \mathrm{P} 25$ for $\mathrm{CO}$ oxidation: effect of working gas. Nanomaterials (2018). https://doi.org/10.3390/nano8090742

44. Deng, X.Q., Zhu, B., Li, X.S., Liu, J.L., Zhu, X., Zhu, A.: Visible-light photocatalytic oxidation of $\mathrm{CO}$ over plasmonic $\mathrm{Au} /$ $\mathrm{TiO}_{2}$ Unusual features of oxygen plasma activation. Appl. Catal. B-Environ. (2016). https://doi.org/10.1016/j.apcatb.2016.01.055

45. Di, L., Zhang, X., Xu, Z., Wang, K.: Atmospheric-pressure cold plasma for preparation of high performance $\mathrm{Pt} / \mathrm{TiO}_{2}$ photocatalyst and its mechanism. Plasma Chem. Plasma Process. (2014). https ://doi.org/10.1007/s11090-013-9515-z

46. Sun, S., Qiu, Y.: Influence of moisture on wettability and sizing properties of raw cotton yarns treated with $\mathrm{He} / \mathrm{O}_{2}$ atmospheric pressure plasma jet. Surf. Coat. Technol. (2012). https://doi. org/10.1016/j.surfcoat.2011.10.005

47. Pawlat, J., Terebun, P., Kwiatkowski, M., Diatczy, J.: RF atmospheric plasma jet surface treatment of paper. J. Phys. D Appl. Phys. 49, 374001 (2016)

48. Mui, T.S.M., Silva, L.L.G., Prysiazhnyi, V., Kostov, K.G.: Polyurethane paint adhesion improvement on aluminum alloy treated by plasma jet and dielectric barrier discharge. J. Adhes. Sci. Technol. (2016). https://doi.org/10.1080/01694243.2015.1099863

49. Kawase, T., Tanaka, T., Minbu, H., Kamiya, M., Oda, M., Hara, T.: An atmospheric-pressure plasma-treated titanium surface potentially supports initial cell adhesion, growth, and differentiation of cultured human prenatal-derived osteoblastic cells. J. Biomed. Mater. Res. (2014). https://doi.org/10.1002/jbm.b.33114

50. Fang, J., Levchenko, I., Mai-Prochnow, A., Keidar, M., Cvelbar, U., Filipic, G., Han, Z.J., Ostrikov, K.: Protein retention on plasma-treated hierarchical nanoscale gold-silver platform. Sci. Rep. (2015). https://doi.org/10.1038/srep13379

51. Wang, R., Xu, H., Zhao, Y., Zhu, W., Ostrikov, K., Shao, T.: Effect of dielectric and conductive targets on plasma jet behaviour and thin film properties. J. Phys. D Appl. Phys. 52, 074002 (2018)

52. Talukde, A.: Plasma Treatment of Zinc Oxide Thin Film and Temperature Sensing Using the Zinc Oxide Thin Film. South Dakota State University, Open PRAIRIE: Open Public Research Access Institutional Repository and Information Exchange, Theses and Dissertations, Paper 1049 (2016)

53. Zendehnam, A., Ghasemi, J., Zendehnam, A.: Employing cold atmospheric plasma ( $\mathrm{Ar}, \mathrm{He})$ on $\mathrm{Ag}$ thin Film and their influences on surface morphology and anti-bacterial activity of silver films for water treatment. Int. Nano Lett. (2018). https:// doi.org/10.1007/s40089-018-0240-8

54. Grigaliūnas, V.: Oxygen-plasma treatment effects nanocomposite silver-poly(methyl methacrylate) films for SPR sensors. In: Conference Paper Radiation Interaction with Material and its use in Technologies (2012)

55. Zhou, R., Zhou, R., Zhang, X., Li, J., Wang, X., Chen, Q., Yang, S., Chen, Z., Bazaka, K., Ostrikov, K.: Synergistic effect of atmospheric pressure plasma and $\mathrm{TiO}_{2}$ photocatalysis on inactivation of Escherichia coli cells in aqueous media. Sci. Rep. (2016). https:// doi.org/10.1038/srep39552

56. Laha, R., Manivannan, A., Kasiviswanathan, S.: Monitoring plasma treatment of thin films by surface plasmon resonance. Rev. Sci. Instrum. (2014). https://doi.org/10.1063/1.4866241

57. Zendehnam, A., Farokhi, B., Beiranvand, N., Miri, S.: Investigation of the statistical surface morphology and optical properties of the $\mathrm{Ag} / \mathrm{Al}$ and $\mathrm{Ag} / \mathrm{Cu}$ thin double-layers. Int. J. Thin Film Sci. Technol. (2013). https://doi.org/10.12785/ijtfst/020304

58. Walsh, J.L., Kong, M.G.: Contrasting characteristics of linear-field and cross-field atmospheric plasma jets. Appl. Phys. Lett. (2008). https://doi.org/10.1063/1.2982497

59. Massines, F., Sarra-Bournet, C., Fanelli, F., Naudé, N., Gherardi, N.: Atmospheric pressure low temperature direct plasma technology: status and challenges for thin film deposition. Plasma Process. Polym. (2012). https://doi.org/10.1002/ppap.201200029

60. Doak, J., Gupta, R.K., Manivannan, K., Ghosh, K., Kahol, P.K.: Effect of particle size distributions on absorbance spectra of gold nanoparticles. Physica E (2010). https://doi.org/10.1016/j.physe .2010 .01 .004

61. Goh, E.G., Xu, X., McCormick, P.G.: Effect of particle size on the UV absorbance of zinc oxide nanoparticles. Scripta Mater. (2014). https://doi.org/10.1016/j.scriptamat.2014.01.033

62. Gupta, P., Ramrakhian, M.: Influence of the particle size on the optical properties of CdSe nanoparticles. Open Nanosci. J. (2009). https://doi.org/10.2174/1874140100903010015

63. Verdeyen, T.: Laser Electronics. Prentice Hall, Englewood Cliffs (1995)

64. Hosseinpour, M., Zendehnam, A.: Externally liquid-filled photonic crystal fibers with high output intensity and low confinement loss. Acta Phys. Pol., A (2017). https://doi.org/10.12693/aphys pola.131.1431

65. Zendehnam, A., Hosseinpour, M., Mirzaei, M., Hedayati, K.: Optimum values of air filling fraction for photonic crystal fibers with different configurations and fixed number of air rings. Appl. Opt. (2014). https://doi.org/10.1364/AO.53.001075

66. Zendehnam, A., Hosseinpour, M., Mirzaei, M., Hedayati, K.: Study of PCF's output intensity profiles with various configurations for low d/ $\Lambda$ values. J. Sci. Res. (2014). https://doi. org/10.3329/jsr.v6i2.16901

67. Waseem, R., Alabastri, S., Zaccariai, R.P.: Surface plasmon resonance sensors: optimization of diffraction grating and prism couplers. In: Proceedings of COMSOL Conference, Rotterdam (2013)

Publisher's Note Springer Nature remains neutral with regard to jurisdictional claims in published maps and institutional affiliations. 